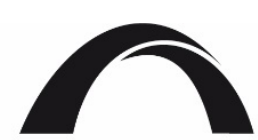

AMSTERDAM CENTER FOR

LAW \& ECONOMICS

\title{
HOW INSTITUTIONS SHAPE MORALITY
}

\author{
Giuseppe Dari-Mattiacci \\ Marco Fabbri
}

Amsterdam Law School Legal Studies Research Paper No. 2021-09

Amsterdam Center for Law \& Economics Working Paper No. 2021-05 


\title{
How Institutions Shape Morality*
}

\author{
Giuseppe Dari-Mattiacci ${ }^{\dagger}$ and Marco Fabbri ${ }^{\ddagger}$
}

March 30, 2021

\begin{abstract}
We present the results of a randomized controlled trial on the effect of the introduction of formalized property rights on individuals' moral judgments and, in particular, on utilitarian morality. We show that institutions shape morality: being exposed to private property institutions makes individuals more utilitarian when confronted with moral dilemmas. Our result sheds light on a possible factor contributing to the variation of moral judgments across the globe and its geographical patterns, and has implications for the consequences of major institutional reforms - both intended, such as land-titling programs, and unintended, such as the fall of
\end{abstract}

*The experiment was approved by the Research Ethics Committee Parc de Salut MAR - Barcelona, reference nr. 2018/8015/I. Participants provided informed consent. The empirical strategy was prespecified in a pre-analysis plan that was registered at the AEA RCT Registry-ID AEARCTR-0005325before we collected the data, and included specification of the hypothesis to be tested and of the regression approach. We are indebted to Deo-Gracias Houndolo for his support during the fieldwork, and to Dr. Charles Ibikounle who provided detailed information on the protection of land in Benin. Ametonou Charmelle, Dossou Fiogbe, Gaston Gnonlonfoun, Issifou Gounou, Colin Henderson, Madeline Holbrook, Nice Houngbegnon, Dorothee Lokossou, Aissath Salifou, Mohamed Sedou, Aparna Sundaram, and Israelia Zannou provided excellent research assistance. We would also like to thank Ben Depoorter, John Donohue, David Enoch, Alon Harel, Keith Hollenberg, Adi Leibovitch, Michael Meurer, Mitch Polinsky, Amber Polk, Chris Robertson, Doron Teichman, Donald Wittman, Kathy Zeiler, and participants in the Law, Economics and Empirical Studies Workshop at Hebrew University of Jerusalem, the Stanford Law and Economics Seminar, and the Law and Economics Seminar at Boston University School of Law. The usual disclaimer applies. Marco Fabbri acknowledges financial support from the Marie Curie Research Grants scheme, grant H2020-MSCA-IF-2017-789596. Giuseppe Dari-Mattiacci gratefully acknowledges research support from Columbia Law School. The authors declare no competing interests.

${ }^{\dagger}$ Corresponding author. University of Amsterdam. E-mail address: gdarimat@uva.nl.

${ }_{\ddagger}^{\ddagger}$ University Pompeu Fabra \& Barcelona GSE \& Amsterdam Center for Law and Economics. 
communism - on moral attitudes. A conjectural channel through which property affects moral judgments is the loosening of social ties.

JEL codes: K11, O13, Z10, Z13.

Keywords: property, utilitarianism, trolley problem, morality, moral machine.

\section{Introduction}

The car you are driving has sudden brake failure and you have only two options. If you go straight, the car will drive through a pedestrian crossing ahead, which will result in the death of 2 men. If you swerve, the car will drive through a pedestrian crossing in the other lane, which will result in the death of 1 man.$^{1}$ What would you do? Is saving two worth the intentional killing of one?

Normative institutional analysis is often predicated on the premise that there are universal moral principles, such as those derived from deontology, as in Rawls (1971), or utilitarianism, as in Singer (2011). In contrast, recent empirical research in psychology and anthropology shows that moral judgments vary over time and space, and are socially functional (Haidt, 2007).2 To sharply characterize moral dilemmas, philosophers have been extensively using trolley problems in thought experiments since the late sixties (Foot, 1967) [3 Their use has now become commonplace also in empirical research (Christensen and Gomila, 2012, Greene, 2016), and the hypothetical above is one of them.

Individuals in different societies tend to give markedly different answers when confronted with moral dilemmas. In the most comprehensive survey so far - the Moral Machine experiment - Awad et al. (2018) collected 40 million decisions from individuals who were exposed to self-driving-car versions of the dilemma above in 233 different societies. They document both geographical variation and correlation with country-level cultural and institutional indicators. In particular, subjects living in countries with individualistic cultures tend to be more willing to accept utilitarian sacrifice, that is, to

\footnotetext{
${ }^{1}$ Hypothetical adapted from vignettes in www.moralmachine.net. See below for more details.

${ }^{2}$ See also Abarbanell and Hauser (2010) (studying moral dilemmas in a rural Mayan societies and showing differences with respect to what is typically observed in other societies), Haidt and Graham (2007) (arguing that there are five distinct psychological systems shaping an individual's emotional reaction to five distinct sets of issues - harm/care, fairness/reciprocity, ingroup/loyalty, authority/respect, and purity/sanctity - which in turn can be seen as determinants of the world's diverse moral landscape), and Enke (2020) (providing evidence of a demand (by voters) and supply (by politicians) of different moral principles, which in turn shaped support for the various candidates in recent US presidential elections). See also more generally on the global variation in behavioral patterns Henrich et al. (2001, 2005).

$$
{ }^{3} \text { See also Thomson 1976, 1984), Kamm 1989), Unger 1996). }
$$
}



swerve in order to spare more lives while intentionally sacrificing some. What explains these patterns? A plausible hypothesis is that, among other factors, legal and economic institutions affect individuals' social environment and hence shape their moral judgments. That is, institutions shape morality.

The notion that morals and, more generally, preferences and culture are endogenous to the institutional setup of society has long been discussed in philosophy (Foucault, 1995), sociology (Elias, 2000), history (Weber, 1976), and economics (Bowles, 1998, Tabellini, 2008a b, Bisin and Verdier, 2011). More recently, empirical analyses and historical casestudies have uncovered the long-term causal effect of institutions on culture (Lowes et al., 2017, Greif and Tabellini, 2017, Enke, 2019, Schulz et al., 2019, Becker et al., 2020, Henrich, 2020). While these studies span generations, in this paper we assess the shortterm effect of a discontinuous institutional change on moral judgments. In particular, we focus on the effect of private property - one of the most fundamental institutions or, possibly, the most fundamental institution of western societies — on utilitarianism.

Private property, especially of land, has been a feature of western legal cultures since antiquity. It was embedded in the legal systems that shaped western law-Roman and canon law - and was central to the thinking of philosophers from Plato, to Thomas Aquinas, John Locke, Thomas Hobbes and Adam Smith (Garnsey, 2014). Over the past several decades, the West has sought to export law and institutions supporting private property of land to developing countries through a series of reforms. The question as to the acceptability of utilitarian sacrifice occupies a similarly prominent role in the West's moral tradition, as it reveals the tension between the maximization of aggregate welfare — as proposed by utilitarians, such as Bentham (1907), Mill (1863) and Singer (2011) - and the relevance of deontological constraints to the admissible means to pursue that goal — as emphasized by utilitarianism's critics, among whom Rawls (1971) and John Paul II (1995). In addition, the extent to which one should embrace the utilitarian calculus has been comprehensively discussed in and is a fundamental issue behind welfarist analyses of laws and institutions, and the disputation about the compatibility of welfare maximization with notions of fairness (see Posner, 1979, Kaplow and Shavell, 2001, and the extensive debate that followed).

While the relationship between private property and morality is not new to economics (see, for instance, Bowles, 1998), assessing empirically its causal effects is challenging

${ }^{4}$ There is a large literature in legal scholarship about how morality (or, more generally, culture) shapes or should shape the law, in general, and property law, in particular (see, for instance, Merrill and Smith. 2007, Dagan and Dorfman, 2016, Zhang, 2016), we focus on the reverse question: how property shapes morality. 

because experiments on the introduction of private property are hard to come by. This limitation applies more generally to studies on the effects of institutional changes on culture and, indeed, the extant literature mostly relies on geographical or historical discontinuities (Lowes et al., 2017, Schulz et al., 2019) 5 In contrast, we present the results of a study that bases identification on a randomized controlled trial.

To sidestep the difficulties inherent in the randomized introduction of private property, we took advantage of the first case in which a property-rights reform was in fact implemented as a randomized control-trial (RCT) in a pool of rural villages in the Republic of Benin. The reform, known as Plan Foncier Rural, consisted in the formalization of previously customary land rights and was implemented in 2010-2011. In the winter of 2020, we presented individuals in treated and control villages with a series of moral dilemmas derived from the Moral Machine experiment.

In our primary vignette, analogous to the one presented above, each individual was asked whether he or she would do nothing and, consequently, continue straight and kill 2 individuals, as opposed to swerving and killing only 1 . In order to save 2 lives, the individual had to take action, which resulted inevitably in the death of a passerby. This setup captures the "negative" side of utilitarianism, that is, the acceptability of harm visited upon innocents - which is commonly referred to as "utilitarian sacrifice" along the path of producing a (greater) good (Kahane et al., 2018) ${ }^{6}$ In a subsequent vignette, the choice was between going straight and killing 1 man versus swerving and killing 2 women. In this case, the utilitarian choice was to continue straight. While the former scenario stacks utilitarianism against preferences for inaction, in the latter scenario utilitarianism is contrasted with gender preferences 7

Our results show that, after only 9 years of exposure to the new property rights regime, villagers are significantly more likely to resolve the moral dilemma in a utilitarian way, that is, to kill 1 rather than 2 individuals. The estimated effects suggest that, on average,

\footnotetext{
${ }^{5}$ See Alesina and Giuliano (2015) for a review of the literature. There is a large literature - including randomized controlled trials - on the effect of market participation on preferences (Jha and Shayo, 2019, Margalit and Shayo, 2020) and morality (Falk and Szech, 2013). We focus on the effects of legal institution rather than market participation.

${ }^{6}$ Globally, individuals tend to prefer inaction to action (Awad et al., 2018). There is also an alternative notion of positive versus negative utilitarianism, which refers to the maximization of benefits versus the minimization of harms (Smart, 1958). This formulation is orthogonal to our discussion.

7 Awad et al. (2018) report a large cross-cultural variance in moral preferences concerning gender. In our data, we found that about $1 / 4$ of the subjects have a preference for sparing a man that is stronger than their preference for inaction; that is, they would rather swerve and spare 1 man than continue straight and spare 1 woman (Vignette 3 in Figure $1 \mathrm{c}$, discussed below in the text). As explained below, in the analysis we control for individual gender preferences.
} 


\footnotetext{
${ }^{8}$ In a contribution based on data collected in 2016-2017 across Beninese villages, Fabbri (2020b) combines an institutional and legal analysis of the Beninese PFR with survey questions and experimental games to show that the reform increased cooperation and trust choices in social dilemmas, but only for those individuals who face relatively low costs to conduct a legal action. In particular, the author shows that the absence of paved roads and difficulties to reach state tribunals magnify the cost of a legal dispute and jeopardize the use of formal courts. The same inverse relationship between the accessibility of state legal institutions and pro-social behavior is reported in Fabbri and Dari-Mattiacci (2020). The authors conduct a modified Dictator game experiment in Beninese rural villages and show that individuals who were awarded private property through the PFR are less likely to steal from peers' endowment, albeit the effects progressively fade away when distance from roads increases.

${ }^{9}$ While Di Tella et al. (2007) assess the effect of "becoming an owner" for a specific group of individuals in a society where property rights are already formalized, we study a formalization of property rights affecting the entire local society, including both those who enjoyed customary property rights prior to the reform and those who did not. While the squatters were given a land title, the reform we consider did not directly redistribute land; in contrast, it primarily concerned the formalization and recording of land titles. (In addition, the formalization occurred after clearing possible disputes as to existing entitlements.). Lastly, their study is based on a quasi-natural experiment - namely, the fact that some owners disputed the re-allocation of property rights in court while others did not - while our design is grounded in a RCT design that randomized the formalization of property rights.
} 
the individuals' social standing with possibly negative repercussions on the security of his or her rights. Utilitarian moral attitudes can be potentially damaging to one's social embeddedness, because the willingness to break with deontological principles may be interpreted as a signal of lack of trustworthiness by group members (Awad et al., 2020). The more an individual's success rests on the social support he or she can gather among the local community, the more costly it is to practice utilitarianism. In contrast, formal property rights that are enforced by an impersonal judiciary and mainly transferred through trade make social ties relatively less important and facilitate utilitarian attitudes (Bowles, 1998, 91-93).

In sum, the introduction of formalized property rights that are upheld by a formal court frees (to some extent) the individual from the need to resort to his or her social relations in order to protect his or her legal rights and economic interests. In turn, this makes the individual less dependent on the stability of social connections and the exhibiting of possibly socially inappropriate moral judgments less costly. Although conjectural, this interpretation is consistent with our finding that those with effective access to justice in formal courts update their moral positions more strongly in response to being awarded property, with the fact that in public goods experiments participants experiencing the Beninese PFR increase contribution for joint projects with strangers outside the village community (Fabbri, 2020a), and with the literature emphasizing the relationship between kin structures, morality and institutions (Ellickson, 1991, Bernstein, 1992, Greif, 1994, André and Platteau, 1998, Bowles, 1998, Henrich et al., 2005, Schulz et al., 2019, Enke, 2019).

The remainder of this paper is organized as follows. In Section 2, we describe the institutional framework and present the details of the Plan Foncier Rural. In Section 3, we discuss our identification strategy, the vignette study, and the data collection procedures. Section 3.4 states the main hypothesis and the empirical specification for testing it. In Section 4, we present our results. In Section 5, we offer a discussion of our findings and their implications, and in Section 6, we conclude with some ideas for future research.

\section{Institutional Framework}

In recent years, systems of formal land ownership registration have been introduced in nearly every African state. Nonetheless, customary land rights still represent the predominant land-tenure arrangement in most rural areas of the African continent. Customary land rights are characterized by a complex set of tenure principles and regulatory mech- 
anisms, usually defined at the village or local level. While a variety of diverse customary arrangements exists, it is possible to identify a set of common features (Delville et al. 2000). Customary rights consist of socially determined land-use rules, where access to land is an integral part of the social structure and tenure is determined by sociopolitical relationships. Governance and enforcement of principles characterizing this system are implemented by local customary authorities. The distribution of land rights is based on the sociopolitical local structure and on family relationships.

This system implies that rights held by individuals are the result of a social and political process of negotiations arbitrated by customary local authorities. This enforcement process has an inherently procedural nature. Rules governing customary arrangements do not provide a precise codification of each landholder's rights. Instead they only state procedures by which an individual obtains access to the land. Therefore, the informal nature of customary rules might be an obstacle to the establishment of secure and welldefined land-property rights. Population growth and the consequent increasing pressure on natural resources create serious concerns for the functioning of informal customary arrangements. Scholars have noticed that the absence of written documentation regarding land use gave rise to increasing conflicts over inheritance and disputes over land use (Deininger and Castagnini, 2006).

In Benin, the policy response to problems due to tenure insecurity has been a landtenure reform known as the Plan Foncier Rural (PFR, henceforth). The reform consists of socio-land surveys at the village level to identify right-holders, their rights, and parcel boundaries. Rights and associated right-holders are then recorded in public registries, and a process of land demarcation takes place. The process allows for public objection to the proposed registration of rights and requires that right-holders and neighbors publicly sign survey records (Hounkpodote, 2007).

According to the PFR roadmap, following the processes of land demarcation and public registry recording, each local administration will then create a public land registry. 10

\footnotetext{
${ }^{10}$ In the original formulation as stated in the Rural Land Act 2007-003, the local administration would also issue the "Certificat Foncier Rural", that is, land certificates that required registration to assign land ownership titles ("Titre Foncier"). Remarkably, in the original formulation of the PFR once the land-demarcation intervention and the recording of rights in a public registry have taken place, the subsequent process of releasing land certificates is purely administrative and does not require further action by landholders. The release of land certificates was de facto interrupted with the enactment of the new Rural Land Law 2013-01 creates a unique ownership document, the "Certificat de Propriete Foncier", that reunifies land certificates and ownership titles. However, as clarified also by Benin State Law 2017-15, even in cases when the local administration has not yet released the certificates, the recorded rights that constitute the basis for the land-demarcation process assign to right-holders the use of rights recognized by courts.
} 


\footnotetext{
${ }^{11}$ See AEA RCT Registry-ID AEARCTR-0005325.
} property rights (Fabbri and Dari-Mattiacci, 2020).

\section{Research Design} analysis ${ }^{11}$

\subsection{The moral dilemmas} death of: ...". that is, they are utilitarian (Kahane et al., 2018).

Given these characteristics, the PFR reform in Benin brought about a major change in the institutional contours of ownership over land by creating a system akin to formalized

The empirical strategy was pre-specified in a pre-analysis plan that was registered at the American Economic Association's Registry for Randomized Controlled Trials before we collected the data. The pre-analysis plan included the specification of the hypothesis to be tested, the regression approach, and the dimensions to be studied in the heterogeneity

To capture utilitarianism in moral judgments we used a series of vignettes that were produced using the Design function on www.moralmachine.net (Awad et al., 2018). The vignettes presented subjects with moral dilemmas consisting of a binary choice between inaction and action, both of which resulted in the death of one or more individuals with varying characteristics. Each vignette presented the heading "The car in the pictures below has sudden brake failure: What would you do if you were driving the car? Choose one of the two options below", followed by two graphic representations of the two options available: Continue straight — "In this case the car will drive through a pedestrian crossing ahead, which will result in the death of: ..." — or Swerve — "In this case the car will drive through a pedestrian crossing in the other lane, which will result in the

Our measure of utilitarianism in moral preferences is based on 2 vignettes constructed by varying the number and characteristics of the individuals put on either path before the car. In Vignette 1 - depicted in Figure $1 \mathrm{a}$ - the choice was between 2 men (if Continue straight was chosen) and 1 man (if Swerve was chosen). Given that individuals tend to attach greater moral weight to action (but see also Abarbanell and Hauser, 2010), choosing to act has a moral cost for the individual, which is greater the greater the weight given to deontological constraints. Therefore, individuals who choose the Swerve option are those with relatively weak moral constraints along the path towards a greater good, 


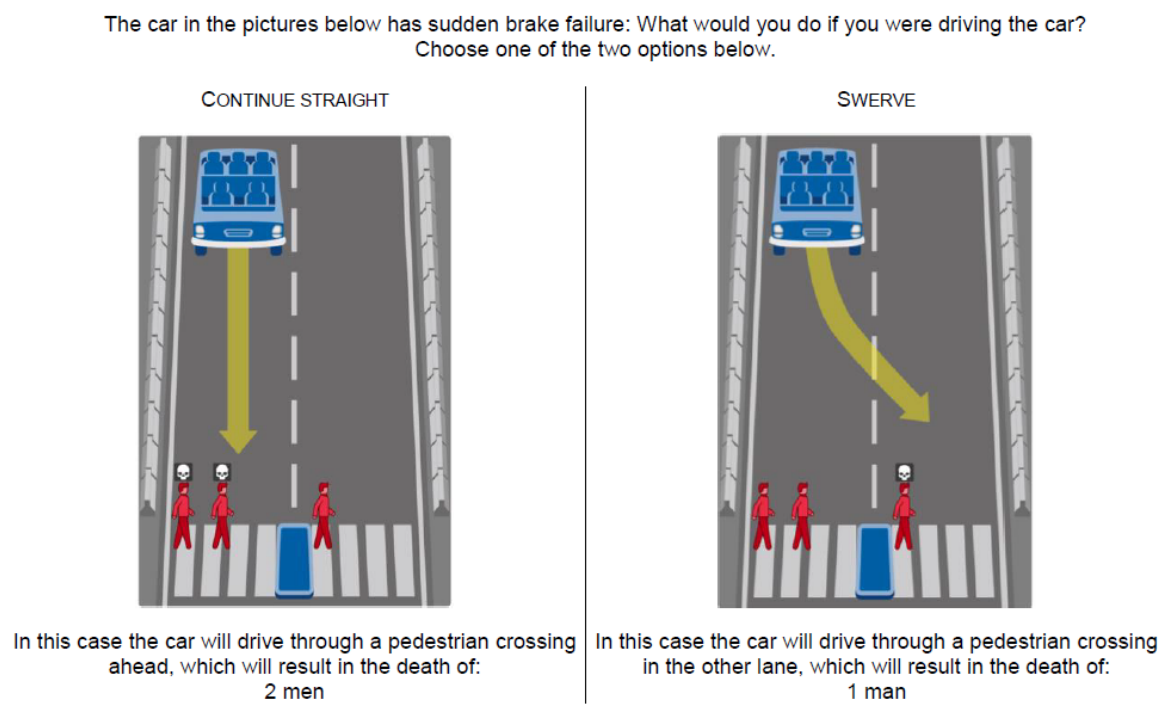

(a) Vignette 1: two men vs. one men

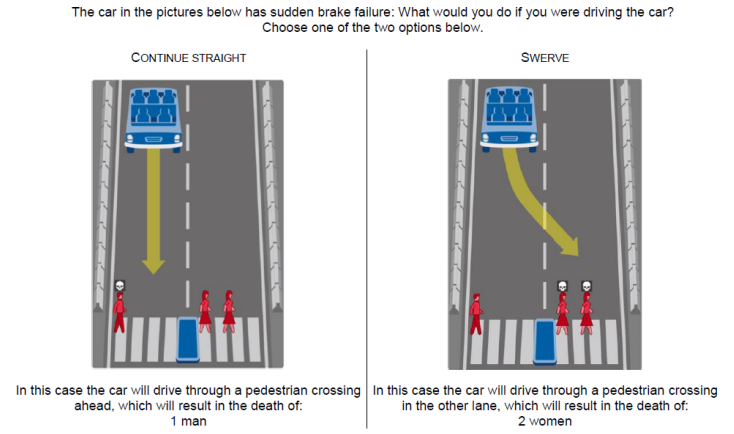

(b) Vignette 2: one man vs. two women

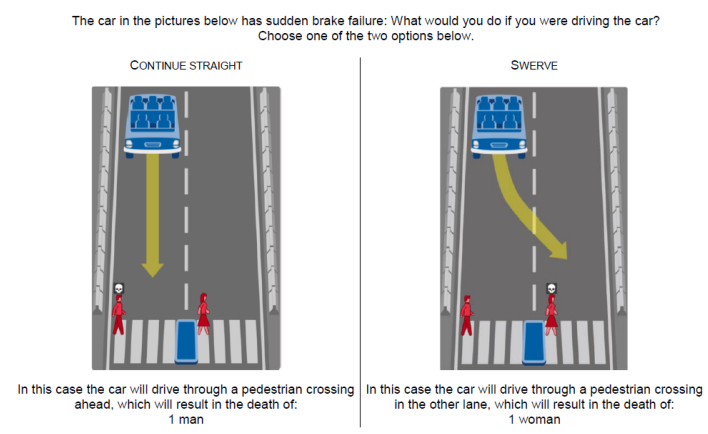

(c) Vignette 3: one man vs. one woman

Figure 1: The vignettes used in the study

The utilitarian dilemma presented in Vignette 2 (Figure $1 \mathrm{~b}$ ) depicts the choice between 1 man (if Continue straight was chosen) and 2 women (if Swerve was chosen). In this case, the utilitarian thing to do is not to act. However, there is evidence that in some cultures subjects have gender preferences for sparing a man (Awad et al. 2018). In this case, the utilitarian choice of swerving would be confronted with a moral cost related to gender preferences. To identify the portion of utilitarian individuals in the population, we combined the answers to vignettes 1 and 2 by classifying an individual as utilitarian only if he or she had chosen to spare 2 individuals in both cases, and as non-utilitarian otherwise.

As we specified in the pre-analysis plan, in the analysis we also account for the indi- 
vidual propensity to spare men versus women displayed by different participants in our sample. We assessed the extent of these preferences in Vignette 3 (Figure1c, which staked 1 man against 1 woman) and we used this measure as a control in the regression analysis. The idea behind introducing the (pre-registered) control for gender preferences is that it captures whether an hypothetical decision to swerve in Vignette 2 (i.e. sparing 1 man vs. 2 women) was only due to utilitarian motives or whether it was additionally influenced by gender consideration (the analysis presented in section 4 shows that excluding this control has no effects on the results) ${ }^{12}$

\subsection{Identification Strategy and Data Collection Procedures}

Due to a lack of resources, the Beninese PFR remained on paper until the Millennium Challenge Corporation (MCC) subsidized an implementation program completed between 2010-2011. In agreement with the World Bank that designed and carried on the impact evaluation of the reform, the implementation followed a RCT process involving hundreds of rural villages. In fact, this is the first case of a large-scale land-tenure reform implemented in this manner (Goldstein et al., 2018).

In the preliminary phase of the project, rural villages were informed of the possibility to have the reform implemented and invited to apply for being included in the RCT pool. As a second step, each application was examined to verify whether the village fit certain eligibility criteria ${ }^{13}$ A total of 576 eligible villages were included in the RCT. Once this pool of villages was identified, a subsample of 300 of them was selected via public lottery, and in these villages the PFR was implemented. The villages that were not selected for the PFR did not receive any intervention and, as of today, continue to have customary land rights. Figure 2 shows a map of the communes and villages where the reform took place.

Our research design is based on the RCT implementation of the reform. From the list of all villages in two regions that were included in the PFR lottery pool, we randomly selected 32 villages where we performed the data collection from a sample of 576

\footnotetext{
${ }^{12}$ In addition to the three vignettes just discussed, during the data collection participants were presented with 6 other vignettes presenting different moral dilemmas in the form of Continue straight versus Swerve. These additional vignettes - depicted in Figures 5 to 10 in Appendix B - were used to introduce an interval between the display of each of the three vignettes decribed in the main text (in the sequence of the nine vignettes in the survey, Vignette 1 was always presented as first, Vignette 2 as eighth, and Vignette 3 as fifth) and to collect additional data we will use in a separate project.

${ }^{13}$ The criteria for eligibility were poverty index, potential for commercial activities, regional market integration, local interest in promoting gender equality, infrastructure for economic activities, adherence to the PFR application procedure, the incidence of land conflicts, and the production of main crops.
} 
participants. For our identification strategy to work, some caveats are in order. First, it is required that there were no pre-treatment differences in moral preferences between treatment groups and that our selection of participants resulted in a balanced sample. We do not have pre-treatment data for treated and control villages included in our sample. This is a limitation of our study. Nonetheless, we believe that our design still provides a credible identification strategy to the extent that we can argue that the implementation of the reform was based on a random selection of treated villages within the lottery pool and that, when analyzing data from our sample of participants, we additionally perform the robustness checks described below.

With respect to the RCT implementation of the reform across Beninese villages, a thorough impact evaluation of the reform carried on by the World Bank reports evidence that the randomization determined by the lottery was successful (Omondi, 2019). In particular, the World Bank team made use of both a rich set of pre- and post-treatment survey data collected by a national agency, as well as of administrative monitoring and evaluation data independently collected by the MCC-Benin. The impact evaluation, resulting from a cross-evaluation performed by using these independently collected data sources, show pre-intervention balance on outcome variables between treatment groups and dispels residual concerns regarding the randomization performed by the lottery selection (Goldstein et al., 2016, Omondi, 2019).

Concerning our sample of participants, we collected data from residents of 32 villages randomly selected among those in the RCT pool. In Table 3 in Appendix A, we report descriptive statistics relative to 20 socio-demographic characteristics for the subjects who took part into the vignette survey. Participants in the treated group are on average older (40 vs. 36.8), more likely to be married ( $89 \%$ vs. $83 \%$ ) and to have running water at home (26\% vs. $18 \%$ ), and show a marginally significantly higher literacy rate (40\% vs. $33 \%$ ) than those in the control group. Notwithstanding that the sample is balanced on the remaining indicators - including income, acres of land owned, and seven other proxies for household's wealth - these individual characteristics might be positive associated with affluence and the imbalance might signal that affluent individuals are over-represented among treated.

We summarize here, and we the details will be reported in the next section, the strategies we adopted to reduce concerns that the results we estimated are biased by affluent individuals self-selecting into the treated group. First, we show that in our sample the variables age, marital status, and having running water (and also, more generally, income levels) are not associated with a larger likelihood to engage in utilitarian choices. 


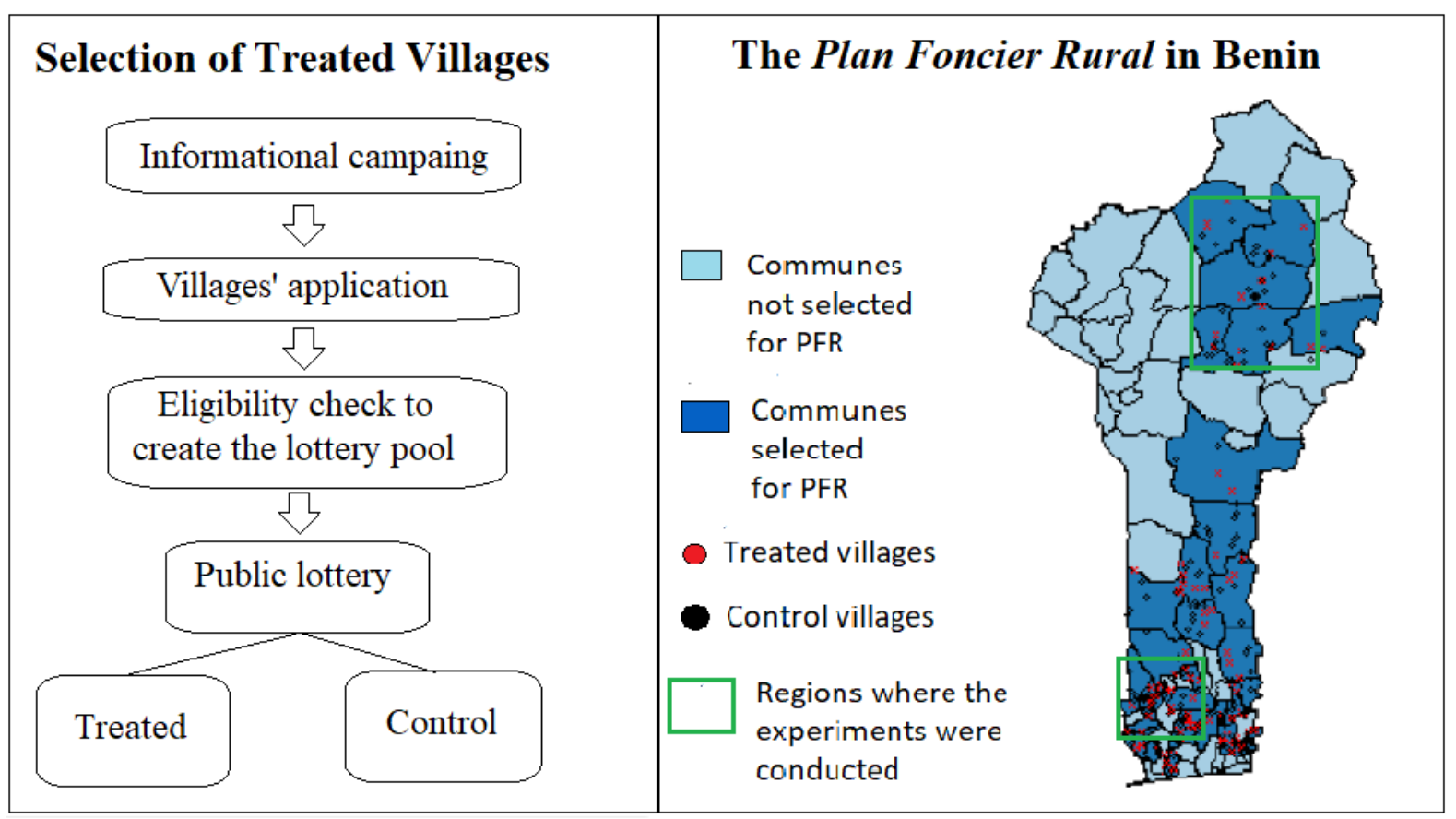

Figure 2: Left Panel: The mechanism for selecting treated villages. Right Panel: Distribution of treated and control villages after the RCT implementation. The green square identifies the provinces where the data collection took place.

Second, we employ a Lasso post-double-selection methodology (Belloni et al., 2014) for appropriately selecting the controls to be included in the regression when accidental imbalances in the sample occurs, so to improve the robustness of our causal inference (Chernozhukov et al., 2018). Finally, we also perform an heterogeneity analysis comparing categories of participants with the same income levels across treatment groups in which we show that, among equally-wealthy individuals, the treatment effects on moral preferences are concentrated on those who were affected the most by the reform.

Furthermore, to dispel concerns regarding self-selection, it is also necessary to show that subjects have not migrated into treated villages following the PFR randomization. As explained in the next section, we have verified that migrating out of the village of origin is rare for participants in our sample and that migration flows are similar across treatment branches.

\subsection{Data Collection Procedures}

Survey participants were recruited during fieldwork sessions in Beninese rural villages. A team of research assistants visited 32 villages that have been randomly selected among 
the list of villages included in the PFR for the regions of Couffou and Mono (in the South of the country) and Alibori and Borgou (in the North). The day before the experiment a research assistant visited the village and requested voluntary participation in the research study to the local population. Among the villagers who showed up at the convened time, we randomly recruited 18 households (9 males and 9 females, older than 18 years old, and maximum one participant per household) for each village, for a total of 576 participants. Non-selected individuals were paid a show-up fee equal to XOF 500 (approximately $\$ 0,85$ ) and were requested to leave.

Each of the 18 participants received a flat participation fee equal to XOF 500 for taking part to the study. The participants took part in the vignette survey to elicit moral decisions described above, in a post-experimental survey, and in other tasks not related to this project. In addition, we collected participants' incentivized measure of risk preferences and socio-demographic information regarding: age, gender, religion, marital status, number of family members, participation to household finance management, literacy, village of birth, years of residence in the village, income, and nine additional proxies for individual wealth 14

\subsection{Main hypothesis and empirical specification}

The main hypothesis tests whether the introduction of formal property rights determined a shift toward utilitarian moral attitudes. This in turn implies a preference for choosing the option that results in sparing the larger number of lives. Therefore, we hypothesize that, in the decisions presented in the appendix:

- In Vignette 1 (Figure 1a), villagers who experienced the reform will spare more often the 2 men than participants in control villages

- In Vignette 2 (Figure 1b), villagers who experienced the reform will spare more often the 2 women than participants in control villages

Hypothesis 1 The land rights reform produces more utilitarian moral preferences.

To test the hypothesis, we construct the dummy variable utilitarian, which takes the value 1 if an individual chooses to spare more lives in the two situations just described,

\footnotetext{
${ }^{14}$ Specifically: hectares of land owned, whether the house has cement floor, whether the household possess either a radio or a television, a motorbike or car, whether in the household somebody holds a bank account or a credit card, whether the house has electricity, whether the house has running water, self-reported rank of socio-economic status within the village.
} 


$$
\text { utilitarian }_{i}=\alpha+\delta_{T} T_{i}+\mathbf{x}_{i}+\epsilon_{i}
$$

where $T_{i}$ is a dummy equal to 1 for subjects in treated villages, and $\mathbf{x}_{i}$ is a vector the individual characteristics specified in the post-experimental survey. As specified in the pre-analysis plan and motivated in section 3.1, we also insert as a control a dummy regarding the outcome of the decision in Vignette 3 (Figure 1c), which identifies those individuals who take a positive action in order to swerve and spare 1 man instead of 1 woman (in the analysis presented in the next section we will show that excluding this control has no effects on the results).

\section{Results}

\subsection{Main Analysis}

We start by verifying that, after the reform implementation, participants had not selfselected through migration into one of the treatment branches. To do so, we collected data regarding participants' village of origin, the number of years they have been living in the village, and the eventual reason leading to migration. The vast majority of participants reside in the same village where they were born $(69 \%$ in treated and $72 \%$ in control, $\chi^{2}$ test $\left.\mathrm{p}>10 \%\right)$. The majority of migrations were reported by female participants, and marriage is the reason commonly declared for the move. The likelihood of having migrated is the same across treatment branches. Finally, we verified that there is no statistically significant difference across treatments between the fraction of adult life a participant had spent in the village where she took part to the data collection (t-test two sided, $\mathrm{p}>10 \%$ ).

\footnotetext{
${ }^{15}$ In the pre-analysis plan, we mentioned that "[S]ince our hypothesis specifies a clear prior regarding the direction of the reform effects, we will apply one-sided tests". Pre-registering that we have theoretical reasons to use a one-sided test would make sense if we are implementing a $z$ test for proportions. However, in the same passage we also mentioned that we would use a Chi-squared test, which is essentially a onesided test (the use of the test as two-sided might generate a fit that is too good, as for instance in the controversy related to the famous Mendel's pea experiments). In practice, the two-tail probability beyond $+/-\mathrm{z}$ for the standard normal distribution equals the right-tail probability above $\mathrm{z}$-squared for the chi-squared distribution with $\mathrm{df}=1$ (Agresti, 2018, p.11). For completeness, we report both the results of a one-sided $z$ test and of a Chi-squared test.
} 


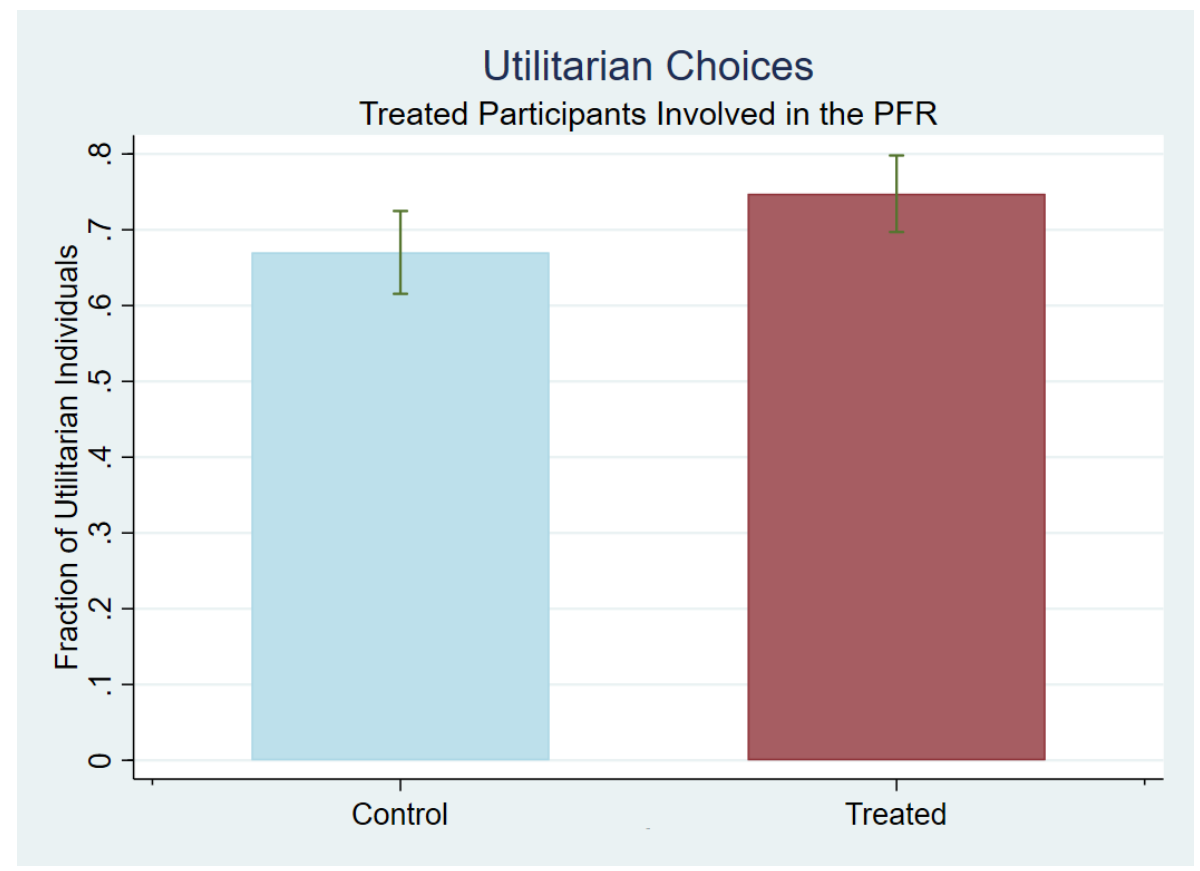

(a) Fraction of Utilitarian Participants

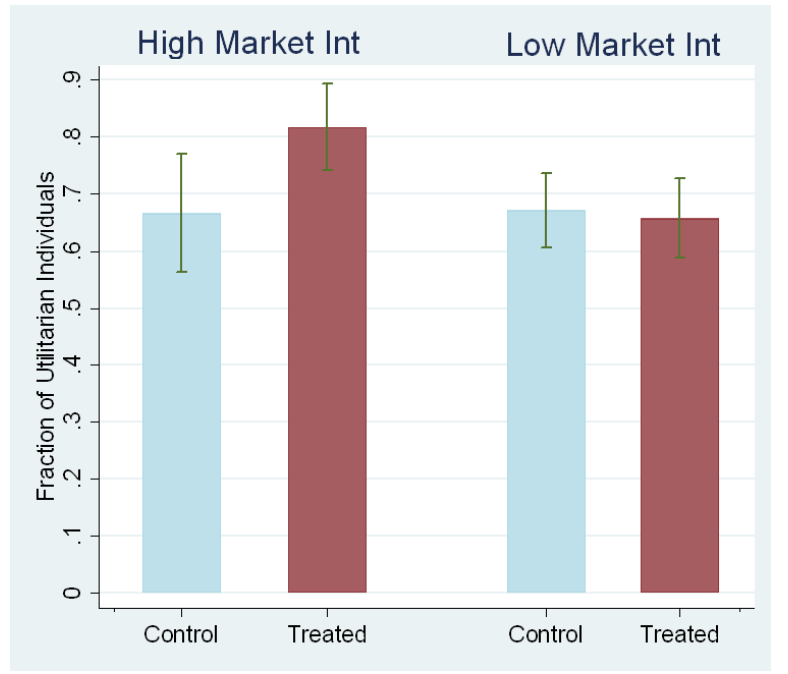

(b) by Market Integration

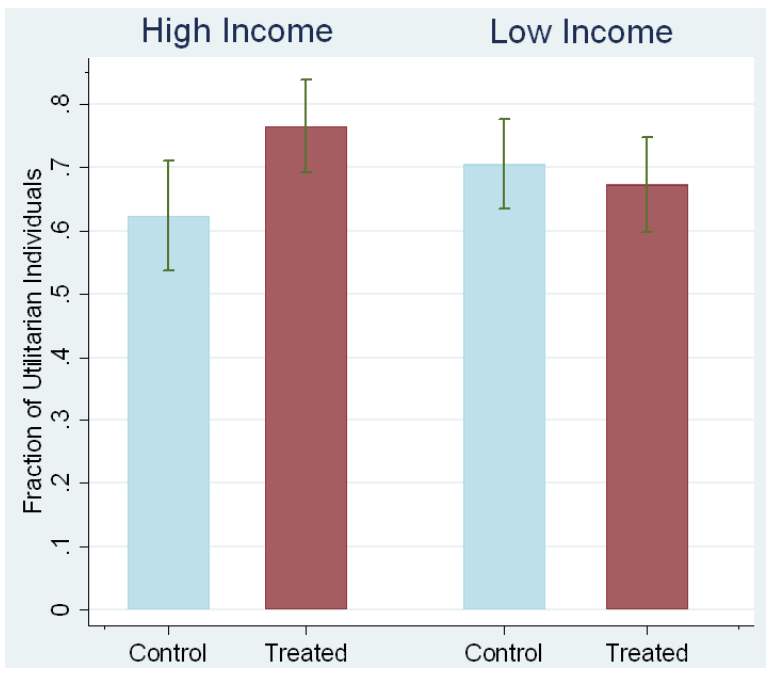

(c) by Income

Figure 3: Utilitarian Participants Across Treatments and Conditions

We begin the analysis by proposing a raw comparison of how many participants report to prefer the two utilitarian options (i.e. sparing the larger number of lives) in villages interested by the land tenure reform and in control villages. Out of a balanced sample consisting of 288 participants for each treatment branch, we have 206 individuals displaying utilitarian choices in treated villages against 193 in control villages. A z-test and chi-squared test show that the difference is not statistically significant. However, a 
Table 1: Utilitarian Participants

\begin{tabular}{lcccc}
\hline \hline & Model 1 & Model 2 & Model 3 & Model 4 \\
\hline treated & $0.380^{* *}$ & $0.465^{* *}$ & $0.479^{* *}$ & $0.580^{* *}$ \\
& $(0.167)$ & $(0.200)$ & $(0.199)$ & $(0.230)$ \\
sparing-man & & $-1.545^{* * *}$ & $-1.559^{* * *}$ & $-1.490^{* * *}$ \\
& & $(0.270)$ & $(0.272)$ & $(0.255)$ \\
dland & & & 0.240 & 0.188 \\
& & & $(0.337)$ & $(0.335)$ \\
Standard-Controls & $\mathrm{Y}$ & $\mathrm{Y}$ & $\mathrm{Y}$ & $\mathrm{Y}$ \\
Wealth-Controls & $\mathrm{N}$ & $\mathrm{N}$ & $\mathrm{N}$ & $\mathrm{Y}$ \\
Constant & 0.923 & $2.214^{* *}$ & $2.189^{* *}$ & $2.511^{*}$ \\
& $(0.876)$ & $(1.025)$ & $(1.037)$ & $(1.285)$ \\
\hline N.obs. & 576 & 576 & 576 & 576 \\
\hline \hline
\end{tabular}

Notes: Dependent variable: Utilitarian. Logit regression. Standard errors robust for clustering at the village level. Standard-Controls included in all regressions: age, gender, religion, marital status, number of family members, participation to household finance management, years of education, whether the village of participation is also the village of birth, years of residence in the village, self-reported weekly income, incentivized measure of risk preferences, village population, distance from paved roads, and whether the village is located in the South. Model 2 adds a dummy for whether the participant took action to spare one man and sacrifice a woman. Model 3 additionally controls for whether participants possess individual land rights; Model 4 adds Wealth-Controls for: hectares of land owned, whether the house has cement floor, whether the household possess either a radio or a television, a motorbike or car, whether in the household somebody holds a bank account or a credit card, whether the house has electricity, whether the house has running water, self-reported rank of socio-economic status within the village (1-10). Symbols $* * *, * *$, and $*$ indicate significance at the $1 \%, 5 \%$ and $10 \%$ level, respectively.

closer look at the post-experimental survey reveals that, among the residents in treated villages who took part to the data collection, 82 individuals did not own land parcels that were included in the land tenure reform and so they have not experienced directly the formalization of property rights. This could happen either because an individual does not possess land at all or because she holds use-rights over land parcels that are located outside of the administrative boundaries of the treated villages, thus in an area not interested by the PFR, which applied exclusively to land parcels within the treated village borders (Goldstein et al., 2018). If we exclude from the sample the 82 residents in treated villages who could have not been affected by the reform, we are left with 154 individuals making utilitarian choices, a fraction significantly larger than in the control (one-sided $z$ test, $\mathrm{p}=3 \%$; Chi-squared test, $\mathrm{p}=6 \%$ ).

We test our hypothesis in a Logistic regression framework. The dummy utilitarian — which is equal to 1 when in both the decisions described above a participant spares the largest number of lives - is regressed on the treatment dummy and a set of socio- 
demographic controls ${ }^{16}$ clustering standard errors at the village level. Model 1 in Table 1 reports the results. The coefficient of the dummy treated is positive and statistically significant at the conventional level, indicating that a larger fraction of villagers in the treated sample is engaging in utilitarian choices. The marginal effects of the estimate coefficient suggests that experiencing the reform increases the likelihood of choosing the utilitarian option by roughly $7 \%$.

We continue the analysis by verifying whether controlling for gender preferences over the individuals to be spared affects the results. Indeed, we know from the results reported by Awad et al. (2018) that there are cross-country and cross-cultural variations concerning preferences for sparing men versus women. In our setting, to be classified as 'utilitarian', a participant must spare the largest number of lives irrespective of whether the individuals to be saved are 2 males (Vignette 1 in Figure 1a) or two women (Vignette 2 in Figure 1a). As specified in the pre-analysis plan and discussed in section 3.1, we account for a participant's gender preferences in the moral dilemma choice by recording data from Vignette 3 in Figure $1 \mathrm{c}$ where participants choose to either sacrifice a male pedestrian or swerve and consequently kill a woman. In model 2 , we then insert as a control a dummy equal to 1 for those participants who decide to take action in order to save the man and sacrifice the woman pedestrian. The qualitative results do not change compared to the basic specification. The point estimate of the treatment variable becomes larger, suggesting that experience with the property rights reform increases the likelihood of being classified as utilitarian by approximately $9 \%$. In model 3 we further add as a control the dummy dland equal to one for participants who took part to the survey but who do not own land parcels that could have been affected by the PFR. This could happen for various reasons, for example because all the land belonging to the household is located outside the village borders - and so not included in the PFR - or because the respondents' household does not possess use-rights over parcels of land at all. The coefficient remains qualitatively and quantitatively similar to the one presented above.

In the context of low-medium-income countries self-reported income might not always be an appropriate proxy for individual wealth (Arrow et al., 2012, Moser and Felton, 2007). Therefore, in model 4 we additionally include as controls a set of nine proxies

\footnotetext{
${ }^{16}$ The controls include: age, gender, religion, marital status, number of family members, participation to household finance management, years of education, whether the village of participation is also the village of birth, years of residence in the village, self-reported weekly income,incentivized measure of risk preferences, village population, distance from paved roads, and whether the village is located in the South.
} 
for individual wealth ${ }^{17}$ The coefficient of the treatment variable remains significant at the conventional level, and the point estimate substantially increases, indicating that participants in villages interested by the reform are on average $10.5 \%$ more likely than those in control villages to make utilitarian choices. In connection to this, we further verify the robustness of our results with respect to the measures of individual wealth we control for. In Table 5 in Appendix A, we re-estimate the specification presented in model 4 by proposing four different proxies of individual wealth. Results remain qualitatively the same and quantitatively very similar to those reported in Table 1.

As discussed in Section 3.2, one potential problem for our empirical strategy is that participants across treatment groups lack balance for some individual characteristics (age, marital status, having running water at home, and marginally literacy) that tend to be positively associated with individual affluence $\sqrt{18}$ We address these concerns by pointing out as a preliminary consideration that among participants in our survey having access to water at home and being married, older, or in general more affluent than the sample median do not increase the frequency of utilitarian choices (two-sided z-test for the four comparisons, $p=.15 ; p=.78 ; p=.33 ; p=.85$, respectively). Notice also that younger people who are over-represented in our control sample actually display higher level of utilitarianism - albeit the difference is not statistically significant.

To mitigate residual concerns, we implement a machine learning tool to select the appropriate controls to be included in the regression analysis. Specifically, we re-estimate the models presented in Table 1 employing the Lasso post-double-selection approach proposed by Belloni et al. (2014) 19 This methodology has been proved useful to select the controls to be included in a regression when accidental imbalances in the sample occurs in a principled way (Belloni et al., 2017, Chernozhukov et al., 2018). Table 4 in Appendix A reports the results. The coefficient of the treatment dummy is confirmed to be significant at the conventional level both in the base model specification (model 1) and when we additionally account for participants in treated villages who does not possess land (model 2). The magnitude of the estimated effect is similar to the one reported in

\footnotetext{
${ }^{17}$ The wealth controls include: hectares of land owned, whether the house has cement floor, whether the household possess either a radio or a television, a motorbike or car, whether in the household somebody holds a bank account or a credit card, whether the house has electricity, whether the house has running water, the self-reported rank of socio-economic status within the village (1-10).

${ }^{18}$ However, notice that in our sample participants older than the median age report on average lower - albeit not statistically different - income levels compared to younger participants.

${ }^{19}$ We additionally replicated the results discussed here by using the Lasso post-regularization methodology proposed by Chernozhukov et al. (2015) and developed as STATA package by Ahrens et al. (2018). Results are virtually identical.
} 


\subsection{Heterogeneity Analysis}

Table 2: Utilitarian Choices - Heterogeneity Analysis

\begin{tabular}{|c|c|c|c|c|c|c|}
\hline \multirow[b]{3}{*}{ Sample: } & Model 1 & Model 2 & Model 3 & Model 4 & Model 5 & Model 6 \\
\hline & \multicolumn{2}{|c|}{ Road Distance } & \multicolumn{2}{|c|}{ Market Integration } & \multicolumn{2}{|c|}{ Income } \\
\hline & High & Low & High & Low & High & Low \\
\hline \multirow[t]{2}{*}{ treated } & 0.452 & $0.814^{* * *}$ & $1.368 * * *$ & -0.135 & $0.820^{* * *}$ & 0.089 \\
\hline & $(0.331)$ & $(0.299)$ & $(0.432)$ & $(0.280)$ & $(0.313)$ & $(0.277)$ \\
\hline \multirow[t]{2}{*}{ spare-man } & $-2.051 * * *$ & $-1.248^{* * *}$ & -0.556 & $-2.186^{* * *}$ & $-1.600 * * *$ & $-1.552 * * *$ \\
\hline & $(0.406)$ & $(0.413)$ & $(0.444)$ & $(0.330)$ & $(0.341)$ & $(0.375)$ \\
\hline \multirow[t]{2}{*}{ dland } & -0.002 & 0.039 & 0.065 & 0.001 & 0.012 & -0.007 \\
\hline & $(0.022)$ & $(0.036)$ & $(0.044)$ & $(0.025)$ & $(0.014)$ & $(0.018)$ \\
\hline Controls & Y & Y & Y & Y & $\mathrm{Y}$ & $\mathrm{Y}$ \\
\hline \multirow[t]{2}{*}{ Constant } & $1.858^{* *}$ & 0.903 & $3.080 * *$ & 1.472 & 0.630 & $2.286^{*}$ \\
\hline & $(0.795)$ & $(1.256)$ & $(1.300)$ & $(1.376)$ & $(0.870)$ & $(1.309)$ \\
\hline N.obs. & 270 & 306 & 188 & 388 & 288 & 288 \\
\hline
\end{tabular}

Notes: Dependent variable: Utilitarian. Logit regression. Standard errors robust for clustering at the village level. Controls included in all regressions: age, gender, religion, marital status, number of family members, participation to household finance management, years of education, whether the village of participation is also the village of birth, years of residence in the village, self-reported weekly income,incentivized measure of risk preferences, village population, distance from paved roads, and whether the village is located in the South. Models 1, 3, and 5 include only the participants living closer to paved road than the sample median, purchasing more than half of the total calorie intake on the market, and reporting a level of income higher than the sample median, respectively. Models 2, 4, and 6 include only the participants not included in Models $1,2,5$. Symbols $* * *, * *$, and $*$ indicate significance at the $1 \%, 5 \%$ and $10 \%$ level, respectively. 


\footnotetext{
${ }^{20}$ One reason why markets and income levels can interact with property in shaping moral preferences is that access to formal courts is costly and hence enforcement of property rights is de facto only available to higher-income individuals.
} 
choices for the subsamples of participants characterized by high and low levels of market integration, respectively. In the high-market-integration subsample, the formalization of property rights significantly and substantially increases utilitarianism. The point estimate suggests an increase of about $19 \%$ for treated participants in the likelihood of being classified as utilitarian compared to control ones. Notice that also in this instance the estimated difference in utilitarian choices cannot be due to differences in income, since we are comparing a subsample of treated and control participants with roughly the same income level (CFA 10,000 vs. 9,200 respectively, $\mathrm{p}>10 \%$ t-test two-sided). Conversely, in the low-market-integration subsample the estimated effect of the reform on utilitarian morality is zero.

The heterogeneity analysis with respect to income levels points to a similar story. In model 5, which isolates the effects of the reform on participants characterized by income levels above the sample median, the coefficient of the treatment dummy is positive and strongly statistically significant, suggesting an estimated $16 \%$ increase in the likelihood of making utilitarian choices for participants experiencing formalized property rights. Once more, by construction here we are comparing a subsample of participants characterized by virtually the same income levels between treatment groups (CFA 16,100 for treated vs. 15,300 for control, $\mathrm{p}>10 \%$ t-test two-sided), thus suggesting that the difference in the levels of individualism observed across the two groups in this subsample does not depend on participants' affluence. Conversely, the estimated effect is statistically indistinguishable from zero for subjects in the low-income subsample, as shown by the coefficient estimate of model 6 .

\section{Discussion}

Our results raise several important questions as to their rationalization and implications, which we address in this section.

\subsection{A conjectural channel: the loosening of social ties}

A natural question to ask is through which channel private property fosters utilitarianism. Here we propose a conjecture: Formal property rights protected by state courts loosen the web of social ties that support the allocation and enforcement of customary rights; in turn, individuals are freed from the need to refrain from socially-alienating moral positions, such as utilitarianism. The link between small communities with strong social ties and 
their ability to operate internal rules of enforcement and conflict resolution outside and sometime even in opposition to formal legal systems has been well documented in several settings (Ellickson, 1991, Bernstein, 1992) and carries with it the opposite implication, that close social ties can be detrimental to the development of impersonal institutions Greif, 1994, Greif and Tabellini, 2017). Here we add a twist to this line of argumentation by suggesting that the introduction of impartial institutions can make social ties less relevant and, as a result, loosen their grip on individuals' moral standings.

To start with, replies to the post-experimental survey by our participants show that the reform resulted in an important increase in material security. We summarize the relevant survey questions and responses in Table 7 in Appendix A. The vast majority of individuals in treated villages appreciate the importance of the reform as protecting rights on land through a system of record-keeping and adjudication in formal courts. Importantly, villagers demonstrate to be well aware of the existence and function of the newly established PFR registries, including their physical location, the possibility to consult them, and their importance as evidence in case of conflicts. Roughly half of the participants have in fact consulted the registry or know somebody who has. Respondents reported to believe that the court system affords effective protection even in the event of a conflict with a more powerful or wealthier individual, suggesting that the reform provided tools for a more effective protection of property rights.

Consistent with this argument, we find that survey responses varied depending on the distance from the closest paved road, a key determinant of effective access to the formal legal system (Fabbri, 2020b). Individuals in villages closer to paved roads that is, closer than the median distance - face substantially lower costs of access to formal courts (with a ratio of 1 to 3 ), and reported to have already had the experience of resolving a land-related dispute in a formal court more often when compared to those farther away. Indeed, easier access to paved roads is associated with substantially more positive responses to the reform along most of the dimensions indicated above. Moreover, individuals closer to paved roads reported a more diffused belief that decisions by formal courts overrule those by customary courts, that disputes should be adjudicated before formal courts rather than before customary courts, and that formal courts are less corrupt than customary courts, as compared to the beliefs held by individuals farther away from paved roads.

Overall, responses to the survey evidence a shared belief that the reform increased material security for those with effective access to formal courts. It has been argued that the lack of material security is a key factor contributing to an individual's parochial- 
ism, that is, his or her tendency to favor a close circle of family, kin or friends over strangers (Hruschka and Henrich, 2013). In turn, an improvement in material security of the kind we discuss above is thought to encourage interactions with strangers outside one's own kith-and-kin community and the expansion of social networks. Indeed, experimental results by one of us (Fabbri, 2020a) document increased levels of cooperation with anonymous strangers belonging to other village communities for individuals who experienced the PFR reform.

The next step in our conjecture is to link the loosening of social ties to an increase in utilitarianism. Awad et al. (2020) argue that utilitarianism is related to relationalmobility, that is, the independent position of an individual vis-a-vis the social network in which he or she lives and operates. Using the Moral Machine platform, they collected the responses of 70.000 subjects in 42 countries to three versions of the classic trolley problem. ${ }^{21}$ They find variation across societies in the acceptability of utilitarian sacrifice and document an association with "relational mobility". In societies where individuals have few opportunities to make new connections and break loose from their original social network, it may be more important to refrain from holding opinions that could potentially alienate friends. Holding a permissive moral position as to the acceptability of utilitarian sacrifice may be considered as a signal of lack of trustworthiness and hence have negative social consequences. As a result, condemnation of utilitarian sacrifice is the more important the more valuable stable social ties are. In this view, morality is deeply "socially functional" (Haidt, 2007) and hence is sensitive to the institutional setup of society.

Other studies also support this point. Schulz et al. (2019) show that church policy banning cousin marriage in the middle ages broke kinship ties, and that kinship ties are negatively related to individualism, which, in turn is shown to be correlated with utilitarian choices (Awad et al., 2018). This suggests that policies that loosen kinship ties tend to result in more individualistic (and possibly utilitarian) attitudes. Similarly, Enke (2019) shows that societies with historically loose kinship ties evolved moral attitudes -

\footnotetext{
${ }^{21}$ Subjects where asked whether it was morally acceptable to kill one in order to spare five in three different scenarios. In the Switch scenario a trolley is heading towards five workers and can be stopped by activating a switch that sends the trolley on a side track, away from the five but en route to one person who will consequently die. In the Loop scenario the side track is a loop and the killing of the one is instrumental in saving the five: his body will stop the trolley. Finally, in the Footbridge scenario, to save the five a large man must be pushed in front of the trolley. They find a universal qualitative ranking of the acceptability of utilitarian sacrifice in these three scenario: Switch is more acceptable than Loop, which is more acceptable than Footbridge. They also found, however, quantitative variation as illustrated in the text.
} 
universal moral values, internalized guilt and altruistic punishment - that are different from those typical of societies with strong kinship ties.

While we stress that this is only a conjecture, we note that the evidence we collected and a broad strand of literature seem to align well with the view that the formalization of property rights resulted in increased utilitarianism through a change in how strongly individuals relate to (and rely on) social connections within their local community.

\section{$5.2 \quad$ (In) commensurability}

Comparing values - such as when choosing between 1 lost life and 2 lost lives — generates a moral dilemma mainly because fundamental values are difficult to compare. Philosophers have pointed to incommensurability as an obstacle to utilitarian choices (Raz, 1988, Chang, 1997). Markets, in contrast, are grounded in the idea that that the goods traded can be compared by means of a common medium, money, and carry with them a psychology of commensurability (Schwartz, 1986).

The property rights reform we study in this paper may be thought as having transformed a resource - the access to which was regulated through a complex system of social control accounting for family needs and redistribution - into a commodity that can be freely traded on the market, and hence has an easily-recoverable monetary value. Because land is one of the — if not the — most important productive asset in rural Benin, the reform may have changed the way individuals regard not only land ownership but "things of value" more generally, making value comparisons easier or more natural and, in turn, utilitarian judgments more acceptable.

Indeed, the effects we measure are more pronounced in individuals who are more reliant on markets. These considerations suggest an additional vector of moral change, which is based on the individuals' psychology and their relationship with goods and values. This channel is consistent — and possibly concurrent — with the loosening of social ties discussed above, which instead focuses on how individuals relate to each other.

\subsection{Co-evolution}

A large literature has emerged in economics around the idea that morality — or, more generally, preferences - and institutions co-evolve (Bisin and Verdier, 2011, Mueller, 2018). While we only document one side of this relationship and, namely, that formal institutions affect morality, others have emphasized the reverse effect, that of morality on institutions. 
Greif (1994) contrasts the close-kin relationship of the Maghribi traders and the more individualistic attitudes of the Genovese traders. While close-kin relationships provided a short-term advantage in terms of enforcement of claims, they also impaired the formation of third-party enforcement systems which eventually favored the Genevose. Enke (2019) emphasizes that the relationship between morality, kinship structure and economic outcomes amplified over time because societies with loose kinship structures developed moral attitudes that facilitated economic development, which in turn furthered the loosening of social ties.

With respect to private property in particular, two studies (Lehavi and Licht, 2011 , Dari-Mattiacci and Guerriero, 2015) found that an individualistic culture tends to result in stronger property rights. A particular characteristic of the language spoken by the plurality group - licence to drop the first-person pronoun in a sentence - is used as an instrument for individualism ${ }^{22}$ Since languages evolved before the formalization of property rights, these studies conclude that culture affects the structure of property rights. Given the cross-country correlation between a utilitarian morality and an individualistic culture (Awad et al., 2018), their and our results suggest that there may be a self-reinforcing co-evolutionary process of utilitarian moral attitudes and formal property rights. Finally, these findings are in line with recent accounts of the institutional, psychological and moral peculiarities of western populations (Henrich, 2020).

\subsection{Positive and negative utilitarianism}

Utilitarianism entails the maximization of aggregate welfare. The implication is that, if to maximize aggregate welfare some harm must be done, which is less than the aggregate gain, then that harm is permissible. A purely utilitarian calculus is unconstrained, that is, it admits the production of any amount of harm as long as there is a corresponding offsetting benefit that balances it. In contrast, deontological moral principles identify harms that are inadmissible no matter the benefit. In this paper, we focus on this specific implication of utilitarianism, that is, individuals' acceptance of utilitarian sacrifice. However, utilitarianism, as a normative ethical theory, is richer than that, which raises the question whether one can extrapolate from an individual's acceptance of utilitarian sacrifice to infer his or her adherence to the broader prescriptions of the theory. The answer is most likely negative.

\footnotetext{
${ }^{22}$ Languages that do not allow dropping the first-person pronoun (such as English) put more emphasis on the individual than languages (such as Italian) were pronoun-drop is allows, which in turns correlates with survey measures of individualism.
} 
Kahane et al. (2018) distinguishes between the general principle of welfare maximization, or the doing of good, which is termed "positive utilitarianism", and its "negative" side, which is related to the production of harm. Put differently, the positive side of utilitarianism embeds a form of moral altruism, where the moral imperative is to accept a personal loss if that allows for the creation of a greater good for somebody else. In contrast, the negative side of utilitarianism embeds the absence or overcoming of deontological constraints to the production of harm for others whenever that harm is instrumental to the generation of a greater good. Kahane et al. (2018) emphasizes that the positive and negative sides of utilitarianism are both philosophically and empirically distinguished, and that moral dilemmas, such as the trolley problems used in this study, are designed to exclusively capture the negative side (acceptability of harm) and carry no weight for the positive counterpart (altruism). Consistently with this approach, in a companion paper (Fabbri and Dari-Mattiacci, 2020), reporting on a previous wave of incentivized experiments in different Beninese villages, we found that the reform had no effect on individuals' altruism.

\section{Conclusions}

In this paper we have showed that the randomized introduction of formal property rights in a pool of Beninese villages resulted in a measurable moral drift towards utilitarianism. Since formal property rights are a key feature of Western economies, our results relate to recent studies on the moral and psychological peculiarities of Westerners (Henrich, 2020), and may contribute a factor explaining the the patterns of geographical variation in moral attitudes across the globe (Awad et al., 2018). While our results focus on land, the past several decades have seen an expansion of property rights in (and propertyrights narratives concerning) intangible assets, such as data and ideas. To the extent that the effects we document are common to other forms of property, these trends may be contributing to the factors pushing western societies towards becoming even more utilitarian, as documented by Hannikainen et al. (2018). In addition, since property rights reforms have been popular over the past few decades, our results imply that they may have also set the reforms recipients on a path of changing moral values.

Our results may also have implications as to the effects of unintended institutional changes. One of the largest and most cataclysmic events in recent history is the fall of communism in the late 80s and early 90s and the demise of the USSR. Alesina and FuchsSchündeln (2007) show that living under communism for 50 years in East Germany made 
individuals believe more strongly that social conditions determine one's fortunes and favor state intervention as compared to the control group of comparable West Germans. They also show that preferences are quickly (re-)converging so that the two groups are predicted to be indistinguishable within 2 generations. One could take the opposite perspective and investigate the effect that the fall (rather than the introduction) of communism had on preferences (and morality). Conspicuously, former communist countries reverted back to formal private property. Our results suggest that morality may have changed in former communist countries after the demise of communism in the same way as it changed in rural Beninese villages.

The effect of property on utilitarianism that we document was measured only 9 years after the reform. This is a remarkably short period of time if compared with the notion of an innate psychology of ownership acquired in early childhood (Nancekivell et al. 2019) and with studies evidencing that moral change in society occurs especially acrossgenerations, with limited effect within-generations (Hannikainen et al., 2018). What explains the short-term effects we detect? Is the long-term impact of the reform even larger or are its full effects already tangible? While we offer a conjecture as to the channels through which formal property affects morality, more research is needed in order to clarify the psychological and sociological mechanisms at work.

\section{References}

Abarbanell, L. and Hauser, M. D. (2010). Mayan morality: An exploration of permissible harms. Cognition, 115(2):207-224.

Agresti, A. (2018). An introduction to categorical data analysis. John Wiley \& Sons.

Ahrens, A., Hansen, C. B., and Schaffer, M. E. (2018). pdslasso and ivlasso: Programs for post-selection and post-regularization ols or iv estimation and inference. Technical report, Statistical Software Components, Boston College Department of Economics.

Alesina, A. and Fuchs-Schündeln, N. (2007). Good-Bye Lenin (or Not?): The Effect of Communism on People's Preferences. American Economic Review, 97(4):1507-1528.

Alesina, A. and Giuliano, P. (2015). Culture and Institutions. Journal of Economic Literature, 53(4):898-944. 
André, C. and Platteau, J. P. (1998). Land relations under unbearable stress: Rwanda caught in the Malthusian trap. Journal of Economic Behavior and Organization, $34(1): 1-47$.

Arrow, K. J., Dasgupta, P., Goulder, L. H., Mumford, K. J., and Oleson, K. (2012). Sustainability and the measurement of wealth. Environment and development economics, 17(3):317-353.

Asher, S., Nagpal, K., and Novosad, P. (2018). The cost of distance: Geography and governance in rural india. World Bank Working Paper.

Awad, E., Dsouza, S., Kim, R., Schulz, J., Henrich, J., Shariff, A., Bonnefon, J.-F., and Rahwan, I. (2018). The moral machine experiment. Nature, 563(7729):59-64.

Awad, E., Dsouza, S., Shariff, A., Rahwan, I., and Bonnefon, J.-F. (2020). Universals and variations in moral decisions made in 42 countries by 70,000 participants. Proceedings of the National Academy of Sciences of the United States of America, 117(5):2332-2337.

Banerjee, A., Duflo, E., and Qian, N. (2020). On the road: Access to transportation infrastructure and economic growth in china. Journal of Development Economics, 145:102442.

Becker, A., Enke, B., and Falk, A. (2020). Ancient Origins of the Global Variation in Economic Preferences. AEA Papers and Proceedings, 110:319-323.

Belloni, A., Chernozhukov, V., Fernández-Val, I., and Hansen, C. (2017). Program evaluation and causal inference with high-dimensional data. Econometrica, 85(1):233-298.

Belloni, A., Chernozhukov, V., and Hansen, C. (2014). Inference on treatment effects after selection among high-dimensional controls. The Review of Economic Studies, 81(2):608-650.

Bentham, J. (1789 [1907]). An introduction to the principles of morals and legislation.

Bernstein, L. (1992). Opting out of the Legal System: Extralegal Contractual Relations in the Diamond Industry. The Journal of Legal Studies, 21(1):115-157.

Bisin, A. and Verdier, T. (2011). The economics of cultural transmission and socialization. In Benhabib, J., Bisin, A., and Jackson, M. O., editors, Handbook of Social Economics. Vol. 1, pages 339-416. Elsevier, Amsterdam. 
Bowles, S. (1998). Endogenous Preferences: The Cultural Consequences of Markets and other Economic Institutions. Journal of Economic Literature, 36(1):75-111.

Casaburi, L., Glennerster, R., and Suri, T. (2013). Rural roads and intermediated trade: Regression discontinuity evidence from sierra leone. Available at SSRN 2161643.

Chang, R. e. (1997). Incommensurability, incomparability, and practical reason. Harvard University Press.

Chernozhukov, V., Demirer, M., Duflo, E., and Fernandez-Val, I. (2018). Generic machine learning inference on heterogenous treatment effects in randomized experiments. Technical report, National Bureau of Economic Research.

Chernozhukov, V., Hansen, C., and Spindler, M. (2015). Post-selection and postregularization inference in linear models with many controls and instruments. American Economic Review, 105(5):486-90.

Christensen, J. and Gomila, A. (2012). Moral dilemmas in cognitive neuroscience of moral decision-making: A principled review. Neuroscience 63 Biobehavioral Reviews, 36(4):1249-1264.

Dagan, H. and Dorfman, A. (2016). Just Relationships. Columbia Law Review, 116(6):1395-1460.

Dari-Mattiacci, G. and Guerriero, C. (2015). Law and culture: A theory of comparative variation in bona fide purchase rules. Oxford Journal of Legal Studies, 35(3):543-574.

Deininger, K. and Castagnini, R. (2006). Incidence and impact of land conflict in uganda. Journal of Economic Behavior \& Organization, 60(3):321-345.

Delville, P. et al. (2000). Harmonising formal law and customary land rights in frenchspeaking west africa. Evolving land rights, policy and tenure in Africa., pages 97-122.

Di Tella, R., Galiant, S., and Schargrodsky, E. (2007). The Formation of Beliefs: Evidence from the Allocation of Land Titles to Squatters. The Quarterly Journal of Economics, 122(1):209-241.

Elias, N. (2000). The civilizing process: sociogenetic and psychogenetic investigations. Blackwell, Hoboken, NJ, 2nd edition. 
Ellickson, R. C. (1991). Order Without Law: How Neighbors Settle Disputes. Harvard University Press, Cambridge, MA.

Enke, B. (2019). Kinship, cooperation, and the evolution of moral systems. Quarterly Journal of Economics, 134(2):953-1019.

Enke, B. (2020). Moral Values and Voting. Journal of Political Economy, 128(10):36793729.

Fabbri, M. (2020a). Institutional Quality Shapes Cooperation with Out-group Strangers. mimeo.

Fabbri, M. (2020b). Property Rights and Prosocial Behavior: Evidence from a Land Tenure Reform Implemented as Randomized Control-Trial. mimeo.

Fabbri, M. and Dari-Mattiacci, G. (2020). The virtuous cycle of property. Review of Economics and Statistics.

Falk, A. and Szech, N. (2013). Morals and Markets. Science, 340(6133):707-711.

Foot, P. (1967). The Problem of Abortion and the Doctrine of the Double Effect. Oxford Review, 5:5-15.

Foucault, M. (1995). Discipline and punish: the birth of the prison. Vintage Books, New York, NY.

Garnsey, P. (2014). Thinking about Property: From Antiquity to the Age of Revolution. Ideas in Context. Cambridge University Press.

Goldstein, M., Houngbedji, K., Kondylis, F., O'Sullivan, M., and Selod, H. (2016). Formalizing rural land rights in west africa: Early evidence from a randomized impact evaluation in benin. World Bank Policy Research Working Paper, (7435).

Goldstein, M., Houngbedji, K., Kondylis, F., O’Sullivan, M., and Selod, H. (2018). Formalization without certification? experimental evidence on property rights and investment. Journal of Development Economics, 132:57-74.

Greene, J. D. (2016). Solving the Trolley Problem. In Sytsma, J. and Buckwalter, W., editors, A Companion to Experimental Philosophy, pages 173-189. John Wiley \& Sons, Ltd, Chichester, UK. 
Greif, A. (1994). Cultural Beliefs and the Organization of Society: A Historical and Theoretical Reflection on Collectivist and Individualist Societies. Journal of Political Economy, 102(5):912-950.

Greif, A. and Tabellini, G. (2017). The clan and the corporation: Sustaining cooperation in China and Europe. Journal of Comparative Economics, 45(1):1-35.

Haidt, J. (2007). The New Synthesis in Moral Psychology. Science, 316(5827):998 LP 1002.

Haidt, J. and Graham, J. (2007). When Morality Opposes Justice: Conservatives Have Moral Intuitions that Liberals may not Recognize. Social Justice Research, 20(1):98116.

Hannikainen, I. R., Machery, E., and Cushman, F. A. (2018). Is utilitarian sacrifice becoming more morally permissible? Cognition, 170:95-101.

Henrich, J. (2020). The WEIRDest People in the World: How the West Became Psychologically Peculiar and Particularly Prosperous. Farrar, Straus and Giroux, New York, NY.

Henrich, J., Boyd, R., Bowles, S., Camerer, C., Fehr, E., Gintis, H., and McElreath, R. (2001). In Search of Homo Economicus: Behavioral Experiments in 15 Small-Scale Societies. American Economic Review, 91(2):73-78.

Henrich, J., Boyd, R., Bowles, S., Camerer, C., Fehr, E., Gintis, H., McElreath, R., Alvard, M., Barr, A., Ensminger, J., et al. (2005). „Äúeconomic man,Äù in crosscultural perspective: Behavioral experiments in 15 small-scale societies. Behavioral and brain sciences, 28(6):795-815.

Hounkpodote, R. (2007). Manuel de procédures pour 1,Ä̂́établissement du plan foncier rural. Cellule opérationnelle Plan foncier rural, MCA-Bénin/GTZ.

Hruschka, D. J. and Henrich, J. (2013). Economic and evolutionary hypotheses for crosspopulation variation in parochialism. Frontiers in human neuroscience, 7:559.

Jha, S. and Shayo, M. (2019). Valuing Peace: The Effects of Financial Market Exposure on Votes and Political Attitudes. Econometrica, 87(5):1561-1588.

John Paul II (1995). Evangelium vitae. Papal encyclical. 
Kahane, G., Everett, J. A. C., Earp, B. D., Caviola, L., Faber, N. S., Crockett, M. J., and Savulescu, J. (2018). Beyond sacrificial harm: A two-dimensional model of utilitarian psychology. Psychological review, 125(2):131-164.

Kamm, F. M. (1989). Harming some to save others. Philosophical Studies, 57(3):227-260.

Kaplow, L. and Shavell, S. (2001). Fairness Versus Welfare. Harvard Law Review, 114:9611388.

Lehavi, A. and Licht, A. N. (2011). BITs and Pieces of Property. Yale Journal of International Law, 36(1):115-166.

Lowes, S., Nunn, N., Robinson, J. A., and Weigel, J. L. (2017). The Evolution of Culture and Institutions: Evidence From the Kuba Kingdom. Econometrica, 85(4):1065-1091.

Margalit, Y. and Shayo, M. (2020). How Markets Shape Values and Political Preferences: A Field Experiment. American Journal of Political Science, XX:XX-XX.

Merrill, T. and Smith, H. (2007). The Morality of Property. Willaim \&s Mary Law Review, 48:1849-1895.

Mill, J. S. (1863). Utilitarianism. Parker, Son, and Bourne, London.

Moser, C. and Felton, A. (2007). The construction of an asset index measuring asset accumulation in ecuador. Chronic poverty research centre working paper, (87).

Mueller, B. (2018). The Coevolution of Institutions and Culture. In Menard, C. and Shirley, M. M., editors, A Research Agenda for New Institutional Economics, pages 153-161. Edward Elgar, Cheltenham.

Nancekivell, S. E., Friedman, O., and Gelman, S. A. (2019). Ownership Matters: People Possess a Naïve Theory of Ownership. Trends in Cognitive Sciences, 23(2):102-113.

Omondi, K. (2019). Mcc evaluation report - ie of access to land project in benin - final. Technical report.

Posner, R. A. (1979). Utilitarianism, Economics, and Legal Theory. The Journal of Legal Studies, 8(1):103-140.

Rawls, J. (1971). A theory of justice. Harvard University Press, Cambridge, MA. 
Raz, J. (1988). The Morality of Freedom. Oxford University Press.

Schulz, J. F., Bahrami-Rad, D., Beauchamp, J. P., and Henrich, J. (2019). The Church, intensive kinship, and global psychological variation. Science, 366(6466):1-12.

Schwartz, B. (1986). Battle For Human Nature: Science, Morality And Modern Life. Norton, New York (NY).

Singer, P. (2011). The expanding circle: Ethics, evolution, and moral progress. Princeton University Press, Princeton, NJ.

Smart, R. N. (1958). Negative utilitarianism. Mind, 67(268):542-543.

Tabellini, G. (2008a). Presidential Address. Institutions and Culture. Journal of the European Economic Association, 6(2-3):255-294.

Tabellini, G. (2008b). The Scope of Cooperation: Values and Incentives. Quarterly Journal of Economics, 123(3):905-950.

Thomson, J. J. (1976). Killing, Letting Die, and the Trolley Problem. The Monist, 59:204-217.

Thomson, J. J. (1984). The Trolley Problem. Yale Law Journal, 94(6):1395-1415.

Unger, P. (1996). Living High and Letting Die. Oxford University Press, Oxford.

Weber, E. (1976). Peasants into Frenchmen: the modernization of rural France, 18701914. Stanford University Press, Stanford.

Zhang, T. (2016). Cultural Paradigms in Property Institutions. Yale Journal of International Law, 41(2):347-413.

\section{A Supplementary Analysis}


Table 3: Balance of Observables Across Treatment Groups ( $\mathrm{t}$ test two-sided for continuous variable and Chi-square test for dummy variables)

$\begin{array}{llll} & \begin{array}{l}\text { PFR Reform } \\ (\mathrm{n}=288)\end{array} & \begin{array}{l}\text { Control } \\ (\mathrm{n}=288)\end{array} & \begin{array}{l}\text { Difference } \\ (\mathrm{p} \text {-value })\end{array} \\ \text { male } & .49 & .51 & .73 \\ \text { age } & 40.0 & 36.8 & .01 \\ \text { muslim } & .45 & .41 & .27 \\ \text { vodoun } & .19 & .18 & .91 \\ \text { married } & .89 & .83 & .02 \\ \text { householdnr } & 9.8 & 10.0 & .68 \\ \text { managefinance } & .95 & .95 & .99 \\ \text { literate } & .40 & .33 & .08 \\ \text { bornvillage } & .69 & .72 & .41 \\ \text { yearsinvillage } & 32.3 & 30.9 & .24 \\ \text { weekly income }(\mathrm{XOF}) & 9,026 & 8,468 & .59 \\ \text { landuse (Hect) } & 5.47 & 5.10 & .65 \\ \text { concretefloor } & .64 & .59 & .23 \\ \text { electricity } & .36 & .36 & .99 \\ \text { water } & .26 & .18 & .02 \\ \text { radio-TV } & .63 & .63 & .99 \\ \text { car } & .09 & .07 & .28 \\ \text { moto } & .77 & .78 & .69 \\ \text { bank-acc } & .33 & .27 & .12 \\ \text { social-rank } & 4.45 & 4.36 & .56\end{array}$

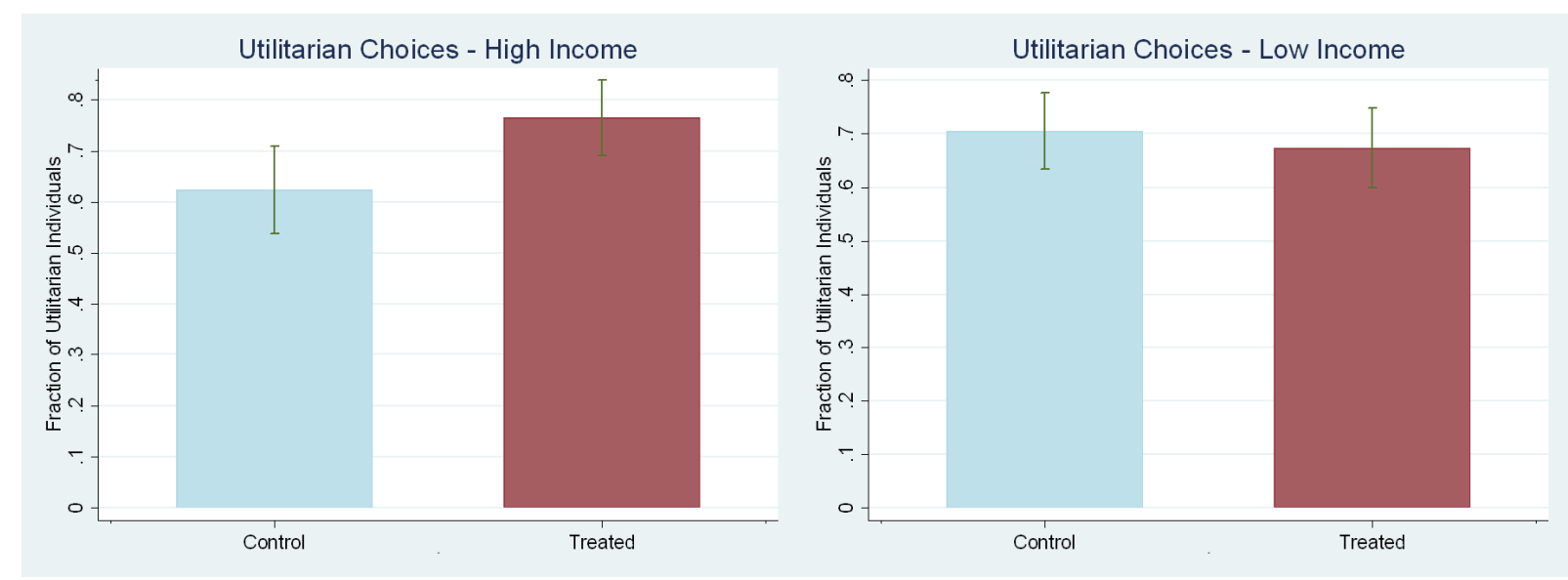

Figure 4: Utilitarian choices comparing across treatment groups participants with high income (left panel) and low income (right panel). 
Table 4: Utilitarian Participants - Lasso Post-double-selection Methodology for Selection of Controls (Belloni et al., 2014)

\begin{tabular}{lcc}
\hline \hline & Model 1 & Model 2 \\
\hline treated & $0.076^{* *}$ & $0.078^{* *}$ \\
managemoney & $(0.034)$ & $(0.033)$ \\
& $-0.228^{* *}$ & $-0.259^{* * *}$ \\
literate & $(0.100)$ & $(0.096)$ \\
& $0.150^{* * *}$ & $0.146^{* * *}$ \\
sparing-man & $(0.037)$ & $(0.036)$ \\
& $-0.332^{* * *}$ & $-0.333^{* * *}$ \\
dist-road & $(0.050)$ & $(0.050)$ \\
& $0.004^{* *}$ & $0.004^{* *}$ \\
south & $(0.002)$ & $(0.002)$ \\
& $-0.116^{* * *}$ & $-0.095^{* *}$ \\
population & $(0.034)$ & $(0.040)$ \\
& -0.000 & -0.000 \\
dland & $(0.000)$ & $(0.000)$ \\
& & 0.058 \\
Constant & & $(0.059)$ \\
& $0.935^{* * *}$ & $0.919^{* * *}$ \\
\hline N.obs. & $(0.114)$ & $(0.120)$ \\
\hline
\end{tabular}

Notes: Dependent variable: Utilitarian. Regularized post-double-selection lasso regression. Standard errors robust for clustering at the village level. High-dim controls included: age, gender, religion, marital status, number of family members, participation to household finance management, years of literate, whether the village of participation is also the village of birth, years of residence in the village, self-reported weekly income, incentivized measure of risk preferences. Models 2 includes as an additional unpenalized control whether participants possess individual land rights. Symbols $* * *, * *$, and $*$ indicate significance at the $1 \%, 5 \%$ and $10 \%$ level, respectively. 
Table 5: Utilitarian Participants - Different Wealth Measures

\begin{tabular}{lcccc}
\hline \hline & Model 1 & Model 2 & Model 3 & Model 4 \\
\hline treated & $0.475^{* *}$ & $0.557^{* *}$ & $0.498^{* *}$ & $0.476^{* *}$ \\
& $(0.196)$ & $(0.231)$ & $(0.212)$ & $(0.206)$ \\
Constant & $2.814^{* *}$ & $2.247^{* *}$ & $2.277^{*}$ & $2.439^{* *}$ \\
& $(1.266)$ & $(1.086)$ & $(1.183)$ & $(1.165)$ \\
\hline \hline N.obs. & 576 & 576 & 576 & 576 \\
\hline \hline
\end{tabular}

Notes: Dependent variable: Utilitarian. Logit regression. Standard errors robust for clustering at the village level. Controls included in all regressions: age, gender, religion, marital status, number of family members, participation to household finance management, years of education, whether the village of participation is also the village of birth, years of residence in the village,incentivized measure of risk preferences, village population, distance from paved roads, and whether the village is located in the South, a dummy for whether the participant took action to spare one man and sacrifice a woman. As a proxy for wealth, model 1 uses self-reported rank of socio-economic status within the village (1-10); model 2 hectares of land owned, whether the house has cement floor, whether the house has electricity, whether the house has running water; model 3 whether the household possess either a radio or a television, a motorbike or car, whether in the household somebody holds a bank account or a credit card; model 4 a compounded index of income (whether above or below the median) and all the elements in models 1-3. Symbols $* * *, * *$, and $*$ indicate significance at the $1 \%, 5 \%$ and $10 \%$ level, respectively. 
Table 6: Utilitarian Participants - Controlling for Conflicts Experienced

\begin{tabular}{lcccc}
\hline \hline & Model 1 & Model 2 & Model 3 & Model 4 \\
\hline treated & $0.382^{* *}$ & $0.468^{* *}$ & $0.500^{* *}$ & $0.436^{* *}$ \\
& $(0.168)$ & $(0.201)$ & $(0.198)$ & $(0.197)$ \\
conflicts & -0.048 & -0.085 & 0.001 & 0.053 \\
& $(0.322)$ & $(0.350)$ & $(0.348)$ & $(0.341)$ \\
sparing-man & & $-1.547^{* * *}$ & $-1.558^{* * *}$ & $-1.638^{* * *}$ \\
& & $(0.260)$ & $(0.250)$ & $(0.271)$ \\
dland & & & 0.300 & 0.338 \\
& & & $(0.334)$ & $(0.331)$ \\
Wealth Controls & $\mathrm{N}$ & $\mathrm{N}$ & $\mathrm{N}$ & $\mathrm{Y}$ \\
Constant & 1.044 & $2.329^{* *}$ & $2.771^{* *}$ & $3.280^{* * *}$ \\
& $(0.902)$ & $(1.074)$ & $(1.252)$ & $(1.210)$ \\
\hline N.obs. & 576 & 576 & 576 & 576 \\
\hline \hline
\end{tabular}

Notes: Dependent variable: Utilitarian. Logit regression. Standard errors robust for clustering at the village level. Controls included in all regressions: age, gender, religion, marital status, number of family members, participation to household finance management, years of education, whether the village of participation is also the village of birth, years of residence in the village, self-reported weekly income,incentivized measure of risk preferences, village population, distance from paved roads, and whether the village is located in the South. Model 2 adds a dummy for whether the participant took action to spare one man and sacrifice a woman. Model 3 additionally controls for whether participants possess individual land rights; Model 4 adds controls for: hectares of land owned, whether the house has cement floor, whether the household possess either a radio or a television, a motorbike or car, whether in the household somebody holds a bank account or a credit card, whether the house has electricity, whether the house has running water, self-reported rank of socio-economic status within the village (1-10). Symbols $* * *, * *$, and $*$ indicate significance at the $1 \%, 5 \%$ and $10 \%$ level, respectively. 
Table 7: Post-experimental Survey (Treated Villages Sample)

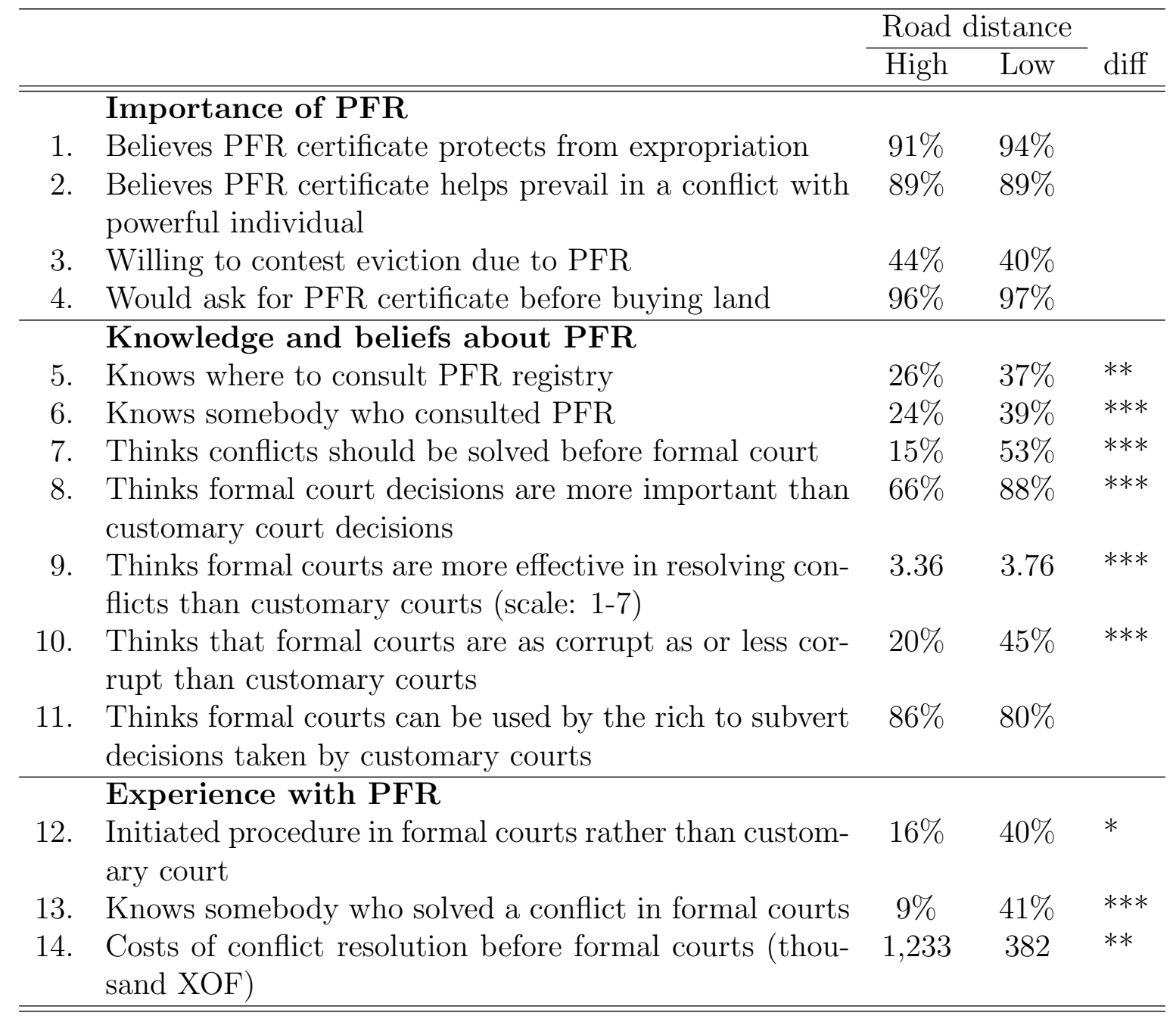

Notes: For each question $\mathrm{N}=276$, except for questions 12 and 14 where $\mathrm{N}=38$ (these questions were posed only to respondents reporting to have had land-related conflicts). Symbols $* * *, * *$, and $*$ indicate significance at the $1 \%, 5 \%$ and $10 \%$ level, respectively. 


\section{${ }_{850}$ B Additional Vignettes Presented During the Field- work}

The car in the pictures below has sudden brake failure: What would you do if you were driving the car? Choose one of the two options below.
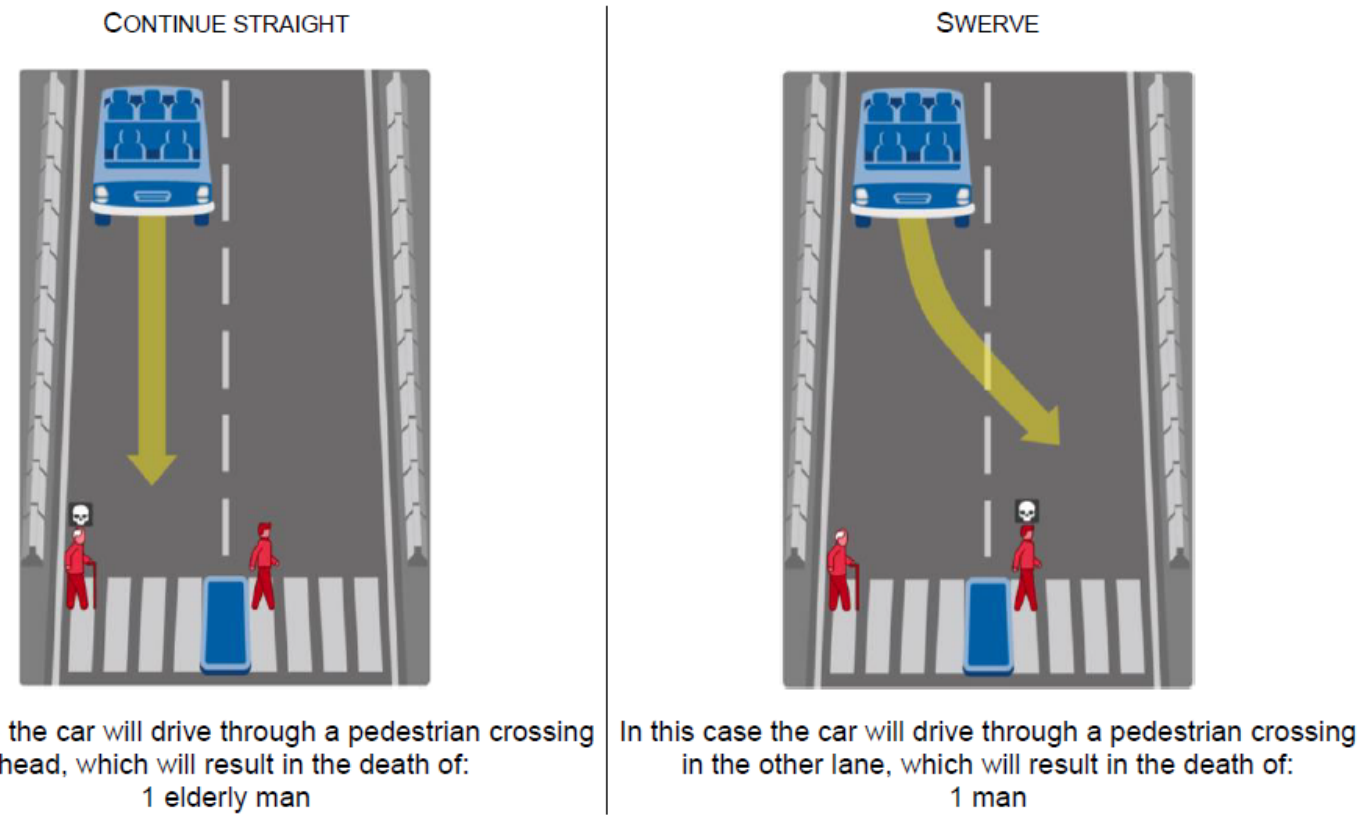

Figure 5: Vignette 4. One elderly men vs. one man 
The car in the pictures below has sudden brake failure: What would you do if you were driving the car? Choose one of the two options below.

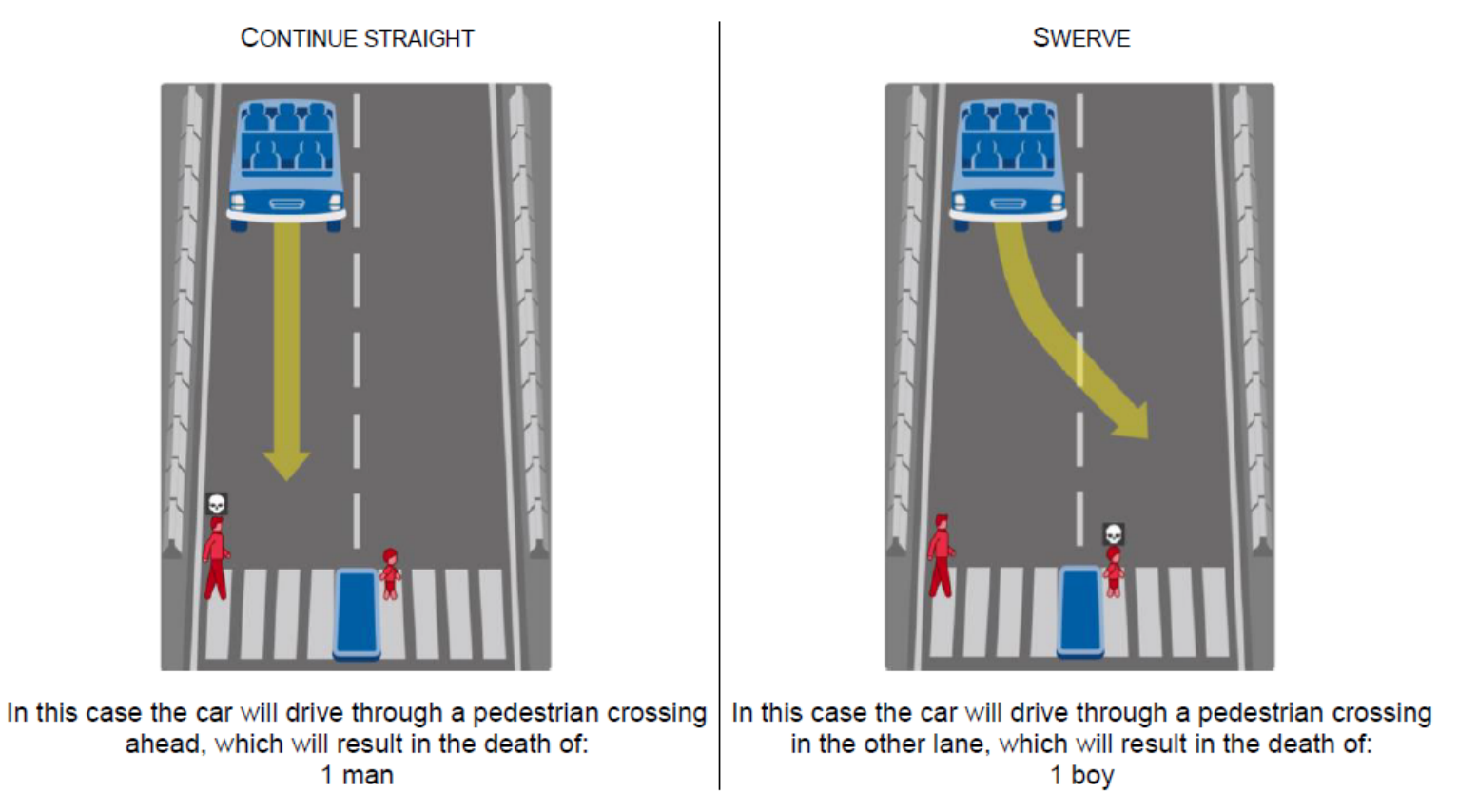

Figure 6: Vignette 5. One man vs. one boy 
The car in the pictures below has sudden brake failure: What would you do if you were driving the car? Choose one of the two options below.

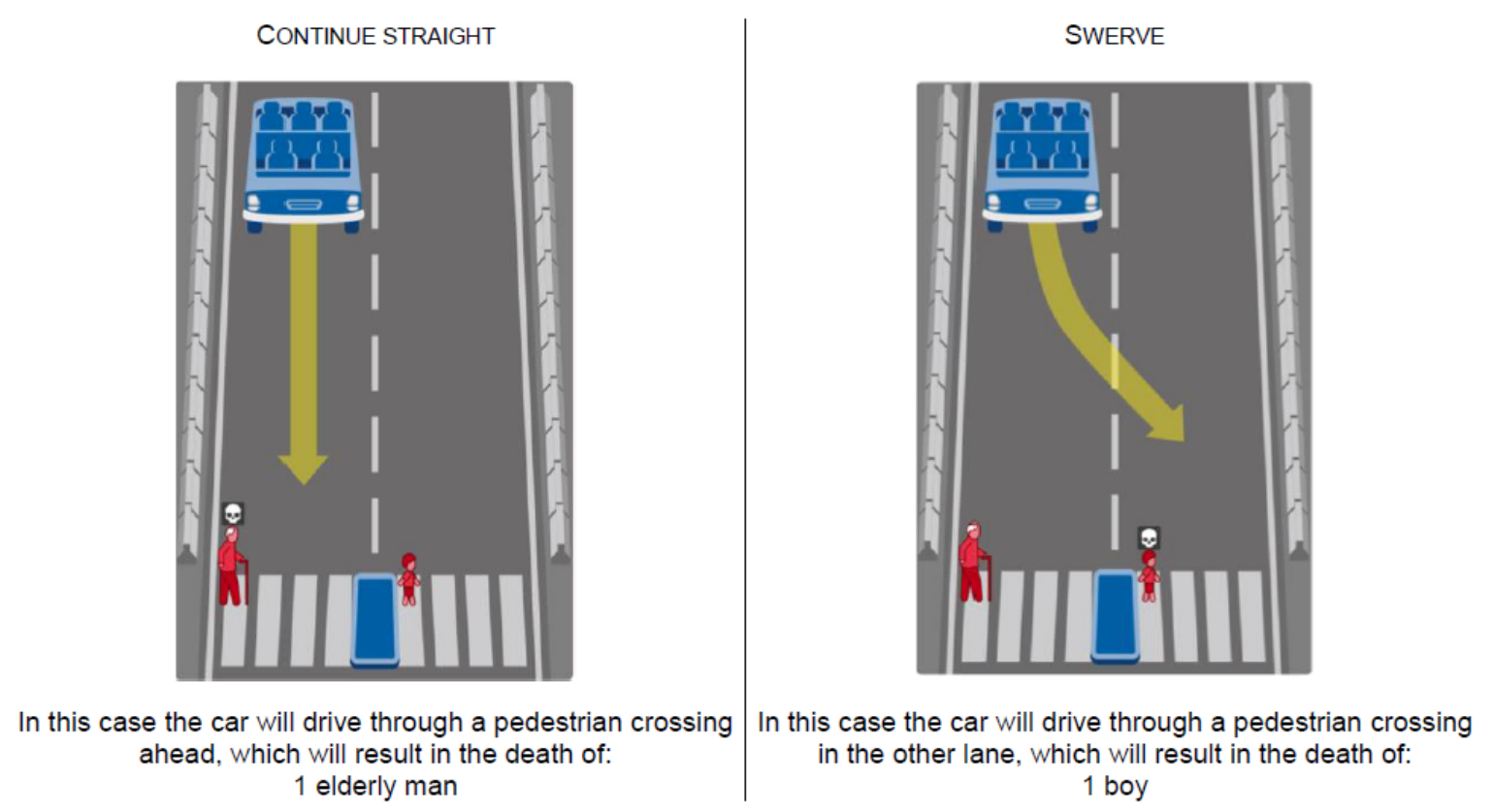

Figure 7: Vignette 6. One elderly man vs. one boy 
The car in the pictures below has sudden brake failure: What would you do if you were driving the car? Choose one of the two options below.

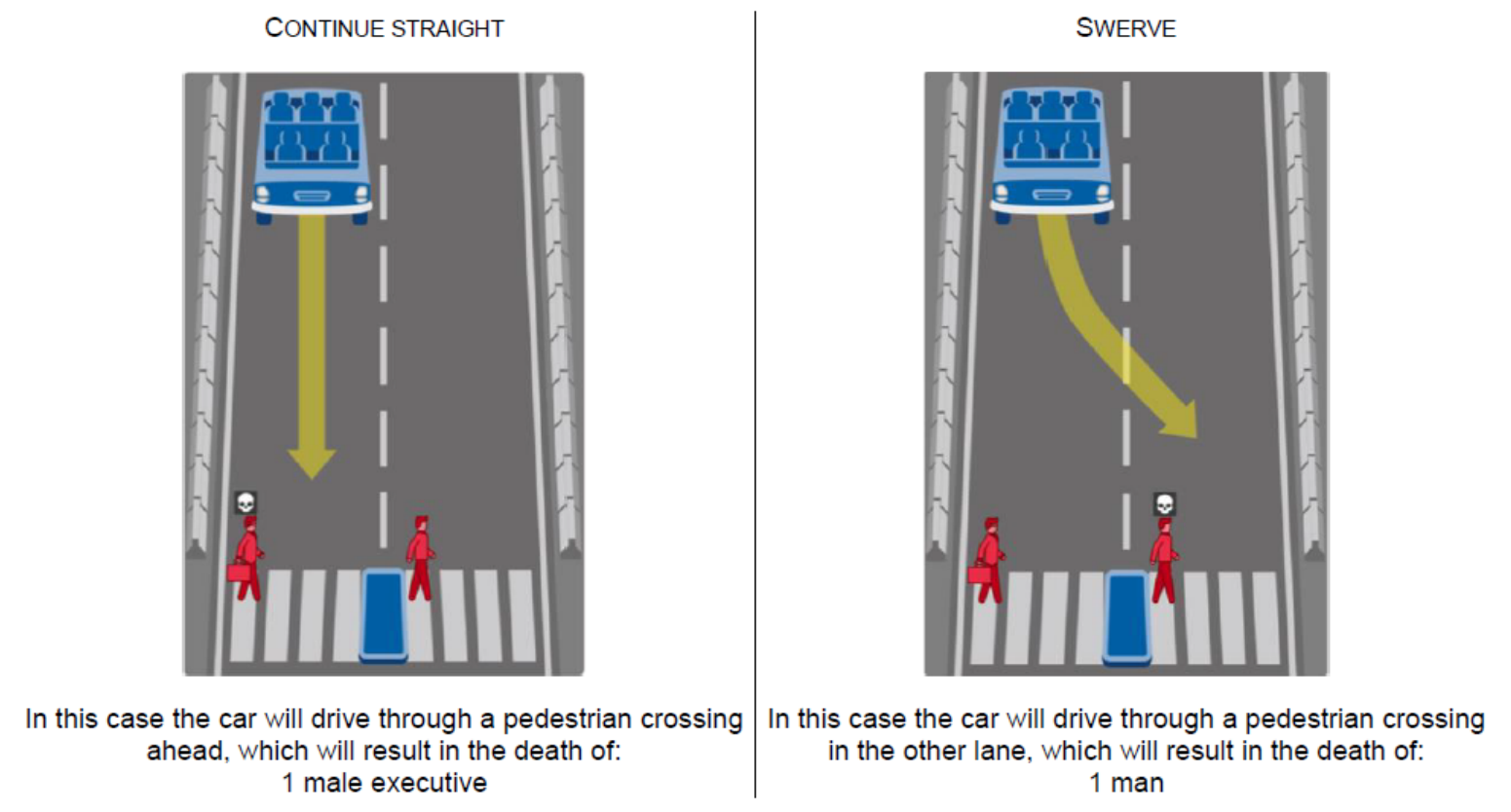

Figure 8: Vignette 7. One male executive vs. one man 
The car in the pictures below has sudden brake failure: What would you do if you were driving the car? Choose one of the two options below.

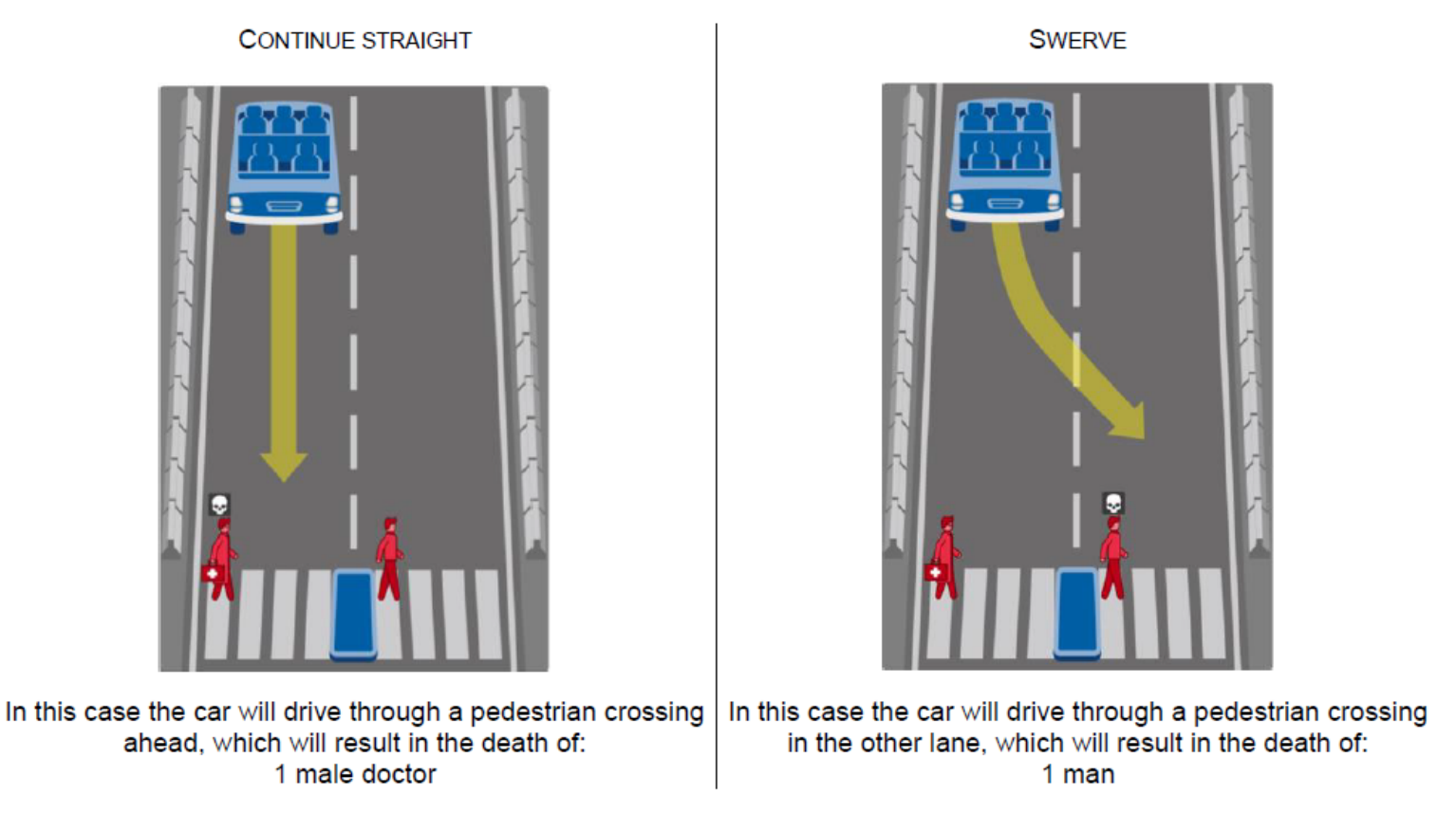

Figure 9: Vignette 8. One male doctor vs. one man 
The car in the pictures below has sudden brake failure: What would you do if you were driving the car? Choose one of the two options below.

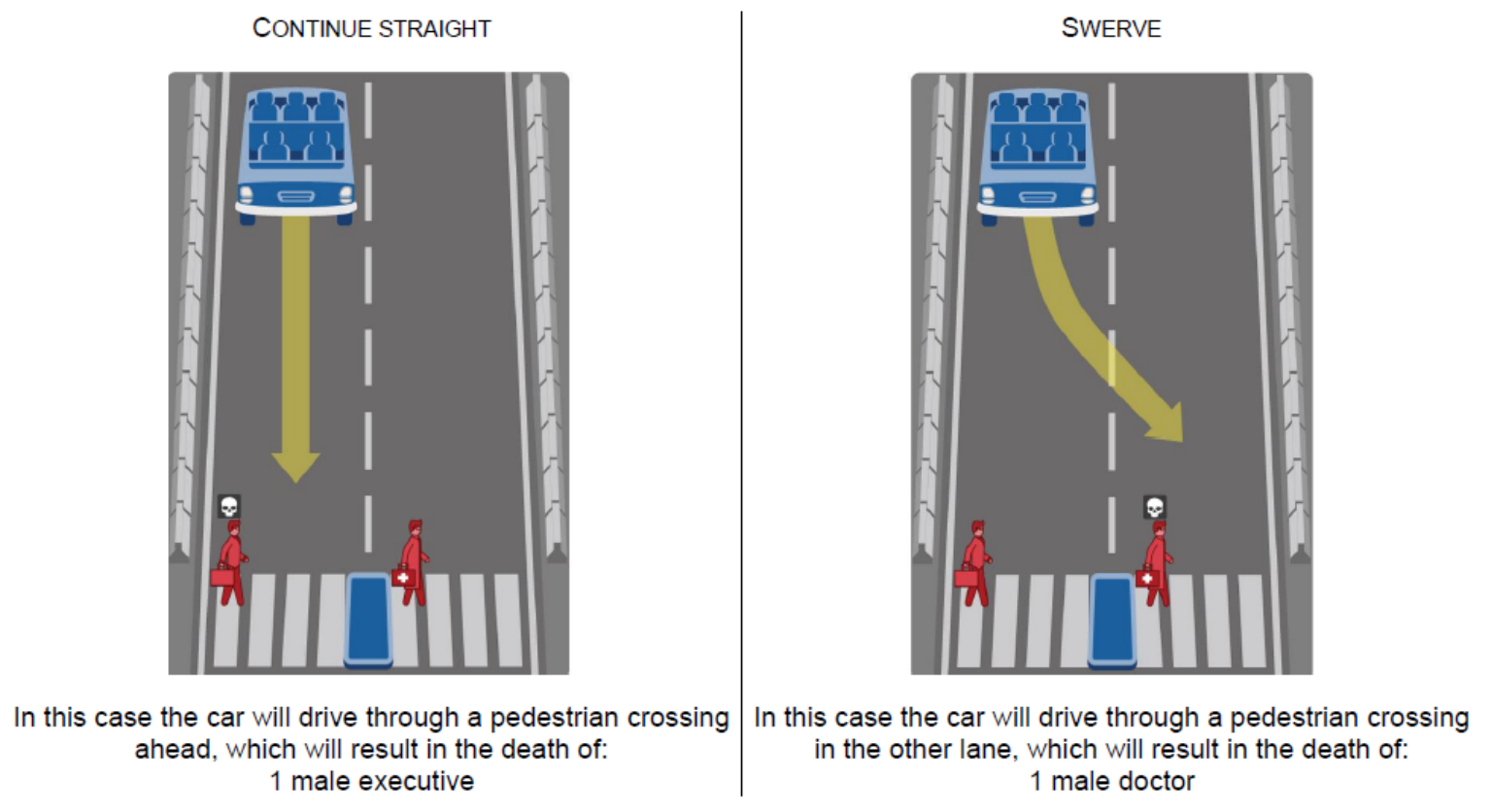

Figure 10: Vignette 9. One executive vs. one doctor 